\author{
Ilza Machado Kaiser
}

\title{
AVALIAÇÃO DE MÉTODOS DE COMPOSIÇÃO DE CAMPOS DE PRECIPITAÇÃO PARA USO EM MODELOS HIDROLÓGICOS DISTRIBUÍDOS
}

Tese apresentada à Escola de Engenharia de São Carlos da Universidade de São Paulo, como parte dos requisitos para obtenção do Título de Doutor em Hidráulica e Saneamento.

Orientador - Prof. Dr. Rodrigo de Melo Porto

São Carlos

2006 
FOLHA DE JULGAMENTO

\section{Candidata Engenheira ILZA MACHADO KAISER}

Tese defendida e julgada em 03-03-06 perante a Comissão Julgadora:

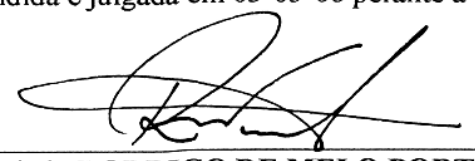

Prof. Associado RODRIGO DE MELO PORTO ( Orientador )

Aprovado

(Escola de Engenharia de São Carlos/USP)

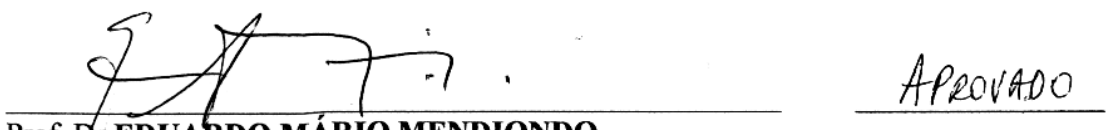

Prof. Dr.EDUARDO MÁRIO MENDIONDO

(Escola de Engenharia de São Carlos/USP)

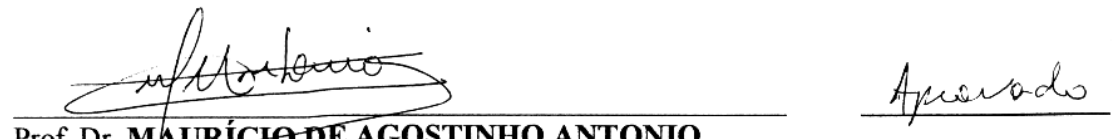

Prof. Dr. MAURÍCIO DE AGOSTINHO ANTONIO

(UNESP/Bauru - SP)

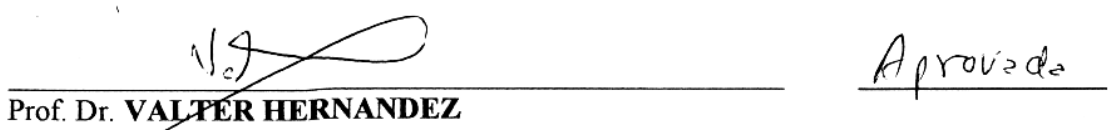

Prof. Dr. VALTER HERNAN

(Universidade Estadual de Campinas/UNICAMP )

VhM m

Prof. Dr. WALTER COLLISCHONN

Epnavado

(Universidade Federal do Rio Grande do Sul/UFRGS)

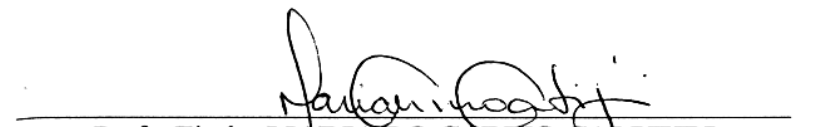

Profa. Titular MARIADO CÂMO CALIJURI

Coordenadora do Programa de Pós-Graduação em

Engenharia (Hidráulica e Saneamento) e

Presidente da Comissão de Pós-Graduação 
Ficha catalográfica preparada pela Seção de Tratamento da Informação do Serviço de Biblioteca - EESC/USP

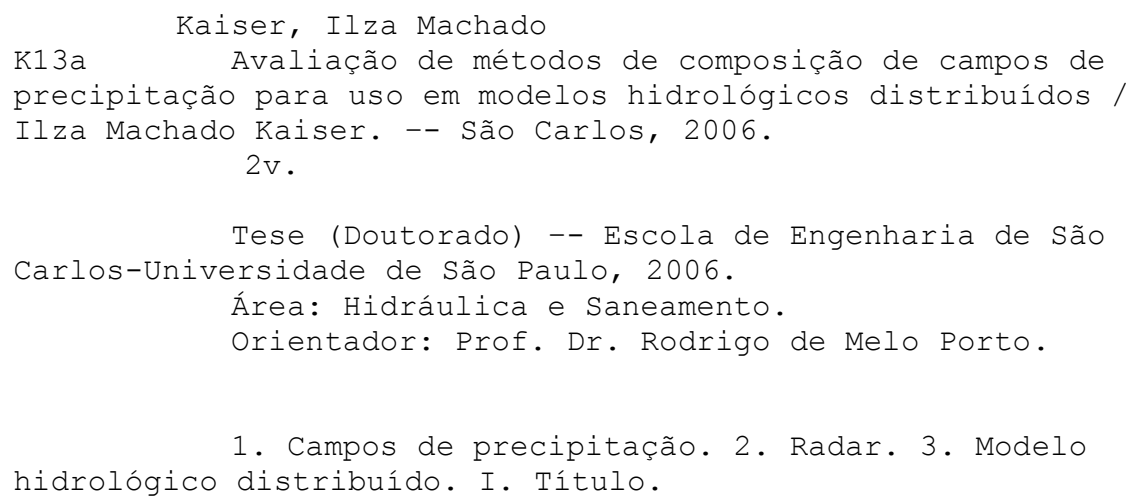


Para Armínio, Jovita, João Roberto e Marina. 


\section{Agradecimentos}

Ao Professor Rodrigo de Melo Porto pela orientação e apoio. Às funcionárias da pós-graduação do departamento de Hidráulica de Sanemento pela atenção em todas as etapas do programa de doutorado.

Ao Dr Walter Collischonn por permitir o uso do modelo hidrológico MGB, ceder os arquivos fonte, e atender prontamente todas as dúvidas que surgiram ao longo do trabalho.

Ao IPMet por ter aberto as portas para a coleta de dados, em especial aos senhores Maurício de Agostinho Antonio, Carlos Alberto de Agostinho Antonio, Hermes Augusto de Godoy França e Marlene Sueli Moia Viani.

À João Roberto Gomes de Faria pelo incentivo e suporte nos mais diversos setores da vida, durante este período e a Marina Kaiser Gomes de Faria pela compreensão. 
"Todo o conhecimento é incerto, inexato e parcial". Bertrand Russel

"Não temos nenhuma certeza absoluta a respeito de um dado processo, a não ser das incertezas a ele inerentes".

Werner Karl Heisenberg 


\section{Resumo}

KAISER, Ilza Machado (2006). Avaliação de métodos de composição de campos de precipitação para uso em modelos hidrológicos distribuídos. Tese (Doutorado) - Escola de Engenharia de São Carlos - Universidade de São Paulo, 2006.

Este trabalho discute a composição de campos de precipitação a partir de duas fontes de dados: os pluviômetros e o radar meteorológico. Estudaram-se métodos baseados somente em dados de pluviômetros, somente em dados de radar, e técnicas que combinam as duas fontes de dados. O objeto de estudo é a bacia do rio Jacaré-Guaçu, que conta com 65 postos pluviométricos e um radar meteorológico, do IPMet-Bauru. Foi feita uma comparação direta entre os campos gerados pelas diversas técnicas, onde foi avaliado o comportamento do índice G (razão entre o registro pluviométrico e a média dos registros de radar dos 9 pixels que circundam o pluviômetro), a capacidade destas técnicas de fornecer a chuva pontual e a altura média diária e anual de chuva por área de integração. Os métodos compostos apresentaram valores pontuais de chuva muito elevados e foram introduzidos fatores limitantes para compensar estas super correções. Os resultados obtidos reproduziram qualitativamente os valores da literatura. Ao analisar a média das chuvas diárias para toda a bacia e para todo o período, utilizando como padrão de comparação o método do Inverso do Quadrado da Distância (IQD), constatou que o radar fornece valores $12 \%$ menores, e que os métodos mistos apresentam diferenças na faixa de $-0,5 a+16 \%$. Nesta forma de análise existe um ganho ao se utilizar as técnicas mistas, porém ao se trabalhar com valores diários, integrados em sub-bacias, as diferenças atingem valores de $-45 \%$ até $+70 \%$. Estes campos de precipitação foram aplicados em um modelo hidrológico distribuído, de embasamento físico, com 19 parâmetros calibráveis. Trabalhou-se com 10 postos fluviométricos e com 6 anos de dados. A calibração foi feita com dois anos e o restante deles foi usado para validação. Para garantir a comparação entre os resultados usou-se rigorosamente a mesma metodologia de calibração, com apoio de algoritmo genético. Foram utilizadas três funções objetivo: uma para verificação dos picos, outra para recessão e a última para avaliar a diferença de volume. Verificou-se que os melhores resultados foram obtidos para os métodos IQD, Brandes com o maior limitador, Radar e Costa. Nestes métodos, o processo de calibração consegue compensar as diferenças dos campos de precipitação. As diferenças observadas nos campos de precipitação foram reproduzidas nos hidrogramas. Os hidrogramas resultantes da aplicação dos dados de radar não reproduziram bem a recessão e os hidrogramas resultantes dos campos gerados apenas por pluviômetros apresentam picos elevados. As técnicas mistas ora atenuam os picos ora intensificam-nos. Sugere-se mais pesquisa para o desenvolvimento de métodos mistos que explorem as vantagens dos dois equipamentos de medida de chuva.

Palavras-chave: Campos de Precipitação; radar; modelo hidrológico distribuído. 


\section{Abstract}

KAISER, Ilza Machado (2006) - Precipitation fields composing methods evaluation for distributed hydrological models use. PhD. Thesis - Escola de Engenharia de São Carlos - Universidade de São Paulo, 2006.

This work discusses the composition of precipitation fields using two data sources: rain gauges and weather radar. Methods based solely on rain gauges, on weather radar, and techniques that combine these two measurement instruments were studied. The study object is the Jacaré-Guaçu river basin, with 65 rain gauges and a meteorological radar (IPMet-Bauru). A direct comparison of these fields generated by diverse techniques was made to study the following subjects: $G$ index (reason between the rain gauge register and the average of the 9 pixels radar registers that surround the rain gauge), the capacity of these techniques to supply the point rain and the daily and annual mean rain height over an integration area. The combined methods provides very high point values, therefore some limitations were introduced to compensate these super corrections. The literature results were qualitatively reproduced in this study. The daily mean rain height comparative analyses for all the basin, and for all the period, evidenced that the radar supplies to values $12 \%$ minors, and that the composed methods present differences from $-0,5$ up to $+16 \%$; the comparison pattern was the Inverse of Square Distance method (ISD). The study of mean rain height calculated over a great period and to the entire river basin shows a profit when using the combined techniques; however, when daily values integrated in sub-basins are used, the differences reach values from $-45 \%$ until $+70 \%$. These precipitation fields had been applied in a distributed hydrologic model, physically based, with 19 calibrated parameters. There were 10 fluviometric stations and 6 years of data. The calibration was made with two years, and that remain data was used for validation. To guarantee the results comparison, the same calibration methodology was rigorously used, with support of genetic algorithm. Three objective functions were used: one for peaks verification, another for recession analyses and the last one for volume difference evaluation. The best results were achieved by the application of the precipitation fields gotten by ISD, Brandes with high limitation, Radar and Costa methods. For these methods, the calibration process compensated the differences on the precipitation fields. The differences observed in the precipitation fields had been reproduced in the hydrograms. The hydrograms of the radar data applications had not well reproduced the recession curve, and the hydrograms of the precipitation fields based only on rain gauges presented high peaks. Sometimes the composed techniques attenuate the peaks, however, sometimes they intensify them. More research is recommended to develop compoud methods that explore the advantages of the two equipments for rain measure.

Keywords: Precipitation fields; radar; distributed hydrological model. 


\section{Lista de Figuras}

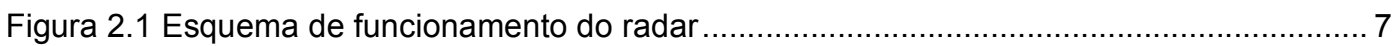

Figura 2.2 Representação dos resultados das varreduras do radar: a) IPP; b) IDA. ................. 8

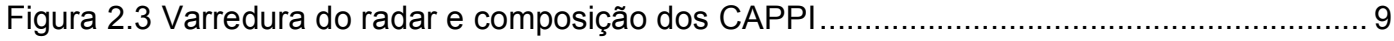

Figura 2.4 Esquema ilustrado da confecção de um IPPAC ........................................... 10

Figura 2.5 Formas de medidas - radar e pluviômetro ................................................... 19

Figura 2.6 Perfis verticais de refletividade para dois eventos típicos: estratiforme e convectivo.

Amostragens feitas em faixas de $20 \mathrm{~km}$ a distancias progressivas do radar. A linha cheia

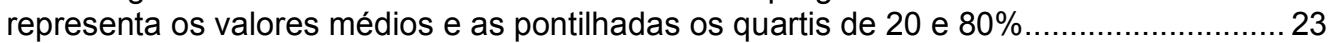

Figura 2.7 Exemplos de tendências e desvios nos resultados de radar e pluviômetros. ........... 42

Figura 3.1 a. Bacia discretizada por quadrículas; b. Bacia discretizada por sub-bacias........... 66

Figura 3.2 Esquema geral de Modelos Distribuídos. .................................................. 68

Figura 3.3 Formas de integração SIG-Modelos Hidrológicos. ............................................. 94

Figura 4.1 Mapa de Localização (sem escala) .......................................................... 99

Figura 4.2 Localização das estações fluviométricas....................................................... 99

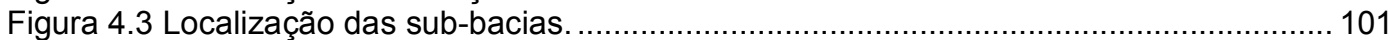

Figura 4.4 Localização das estações pluviométricas ................................................ 101

Figura 5.1 Localização do radar de Bauru. Raio interno 240 km e externo 450 km............. 110

Figura 5.2 Unidades de Gerenciamento de Recursos Hídricos do Estado de São Paulo....... 116

Figura 5.3 Localização da bacia em estudo - Jacaré-Guaçu. ......................................... 117

Figura 5.4 Bacia do Jacaré-Guaçu. Rios formadores e núcleos urbanos. ............................ 118

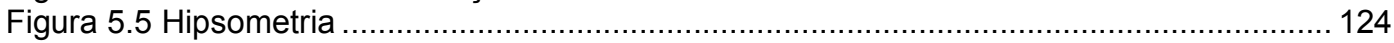

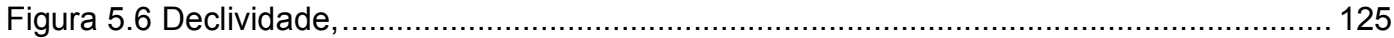

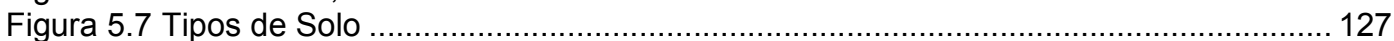

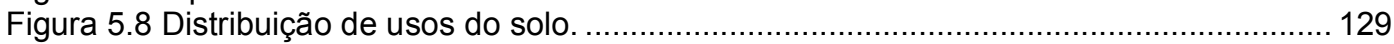

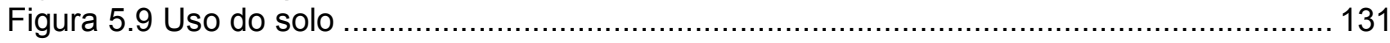

Figura 6.1 Distribuição da ocorrência de blocos de categorias de usos do solo ..................... 137

Figura 6.2 Distribuição de ocorrência dos blocos de uso. .................................................. 138

Figura 6.3 Relação entre a largura do rio e a área de drenagem da bacia ........................... 157

Figura 7.1 \% distribuída de ocorrência de G - MP - jan-fev - 95 .................................... 164

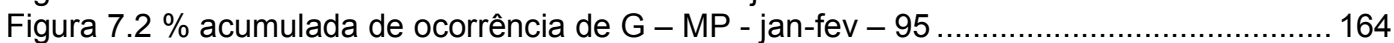

Figura 7.3 \% distribuída de ocorrência de log(G) MP - jan-fev - 95............................... 164

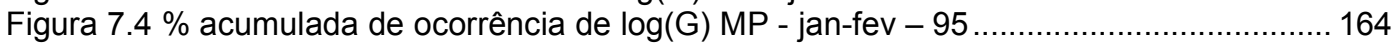

Figura 7.5 \% distribuída de ocorrência de G MP - jun a ago - 1995 ................................. 164

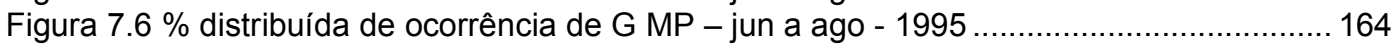

Figura $7.7 \%$ distribuída de ocorrência de log(G) MP - jun a ago - 1995 ............................ 165

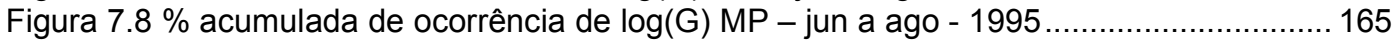

Figura 7.9 \% distribuída de ocorrência de G MP - jan-fev - jun a ago - 1995 ....................... 165

Figura 7.10 \% distribuída de ocorrência de G MP - jan-fev - jun a ago - $1995 \ldots \ldots \ldots \ldots \ldots \ldots \ldots . . . . . . . .165$

Figura $7.11 \%$ distribuída de ocorrência de log(G) MP- jan-fev - jun a ago - 1995................ 165

Figura $7.12 \%$ acumulada de ocorrência de $\log (\mathrm{G}) \mathrm{MP}$ - jan-fev - jun a ago - 1995............. 165

Figura $7.13 \%$ distribuída de ocorrência de G MP - 1995 completo ..................................... 165

Figura 7.14 \% acumulada de ocorrência de G MP - 1995 completo ................................... 165

Figura 7.15 \% distribuída de ocorrência de $\log (\mathrm{G})$ MP- 1995 completo ............................... 166

Figura 7.16 \% acumulada de ocorrência de $\log (\mathrm{G})$ MP - 1995 completo .............................. 166

Figura $7.17 \%$ de ocorrência distribuída de G - Antonio - jan-fev - 1995 .............................. 166

Figura $7.18 \%$ de ocorrência acumulada de G - Antonio - jan-fev - 1995 ........................... 166

Figura $7.19 \%$ de ocorrência distribuída de $\log (\mathrm{G})$ - Antonio- jan-fev - $1995 \ldots \ldots \ldots \ldots \ldots \ldots \ldots \ldots . . . . . . . .166$

Figura $7.20 \%$ de ocorrência acumulada de $\log (\mathrm{G})$ - Antonio - jan-fev - $1995 \ldots \ldots \ldots \ldots \ldots \ldots \ldots . . . . . . . .166$

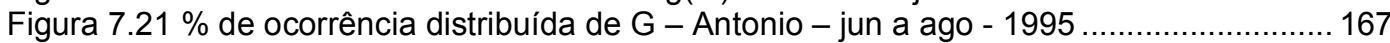

Figura $7.22 \%$ de ocorrência acumulada de G - Antonio - jun a ago - 1995 ....................... 167

Figura $7.23 \%$ de ocorrência distribuída de $\log (\mathrm{G})$ - Antonio - jun a ago - 1995 ................... 167

Figura $7.24 \%$ de ocorrência acumulada de $\log (\mathrm{G})$ - Antonio - jun a ago - 1995 ................... 167

Figura $7.25 \%$ de ocorrência distribuída de G - Antonio - jan-fev - jun a ago - 1995 ............. 167

Figura $7.26 \%$ de ocorrência acumulada de G - Antonio - jan-fev - jun a ago - 1995 ........... 167

Figura $7.27 \%$ de ocorrência distribuída de $\log (\mathrm{G})$ - Antonio - jan-fev - jun a ago - 1995 ...... 167

Figura 7.28 \% de ocorrência acumulada de $\log (G)$ - Antonio - jan-fev - jun a ago - 1995 ..... 167

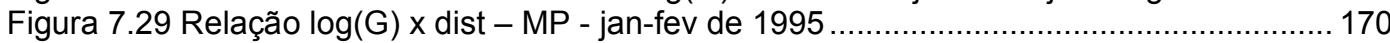

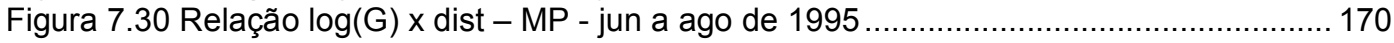




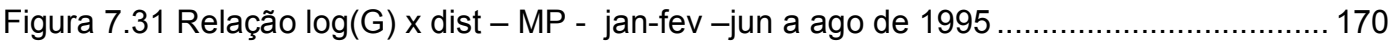

Figura 7.32 Relação $\log (\mathrm{G})$ x dist - MP - ano completo ................................................ 170

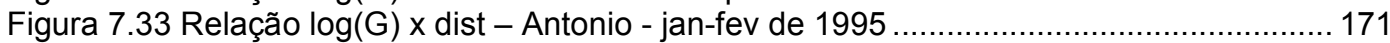

Figura 7.34 Relação $\log (G)$ x dist - Antonio - jun a ago de 1995 ...................................... 171

Figura 7.35 Relação $\log (\mathrm{G})$ x dist - Antonio - jan-fev - jun a ago de 1995 ............................. 171

Figura 7.36- Localização das estações retiradas do estudo piloto .................................... 173

Figura 7.37 Coeficientes de determinação $\left(R^{2}\right)$. Análise espacial - janeiro-fevereiro 1995. ... 175

Figura 7.38 Coeficientes de determinação $\left(R^{2}\right)$. Análise espacial - junho a agosto $1995 \ldots \ldots . .176$

Figura 7.39 Coeficientes de determinação $\left(R^{2}\right)$ - Análise temporal - janeiro e fevereiro 1995.

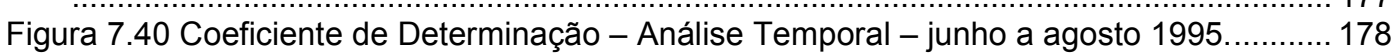

Figura 7.41 Volume de chuva diário na bacia .............................................................. 180

Figura 7.42 Duplas Massas - Volume acumulado x Volume acumulado pelo método do

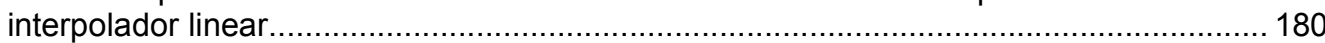

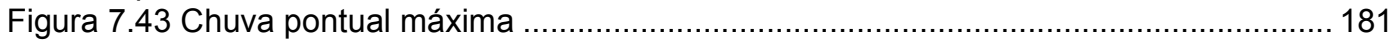

Figura 7.44 Coeficientes de correlação de valores máximos pontuais versus área............... 185

Figura 7.45 Localização das bacias com melhor índice de correlação .................................. 185

Figura 7.46 Coeficientes de correlação - Valores máximos pontuais - Bacia total.................. 186

Figura 7.47 Máximos valores pontuais em função da área. .......................................... 187

Figura 7.48 Valores pontuais máximos - período integral - bacia total. .............................. 187

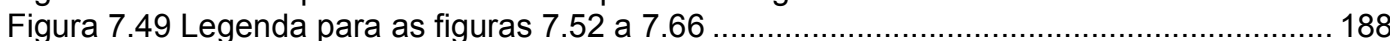

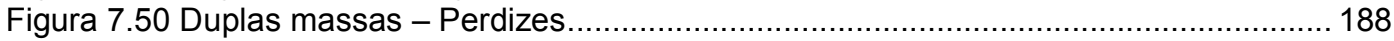

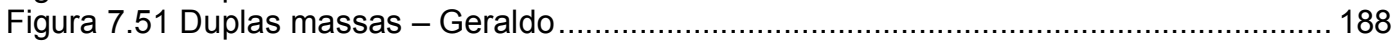

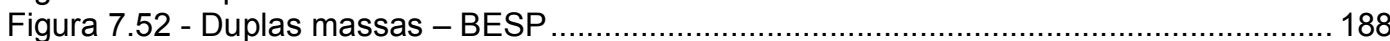

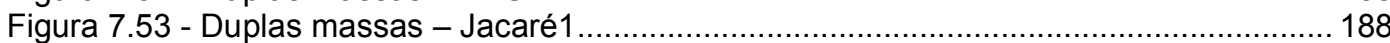

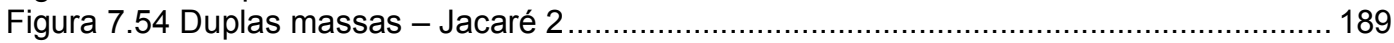

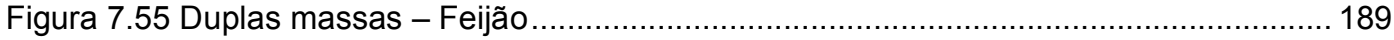

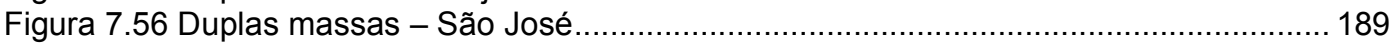

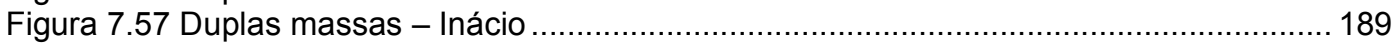

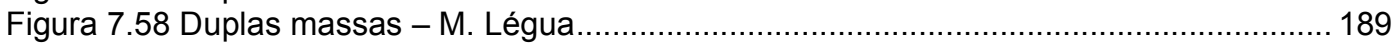

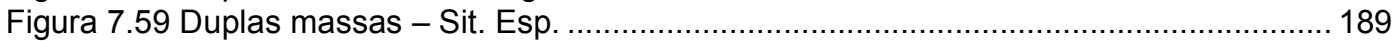

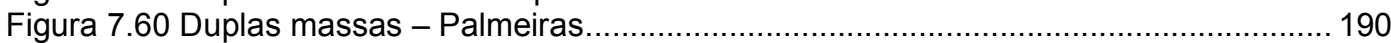

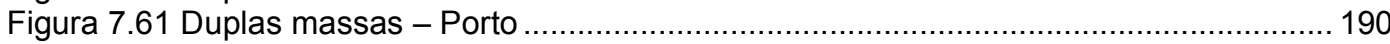

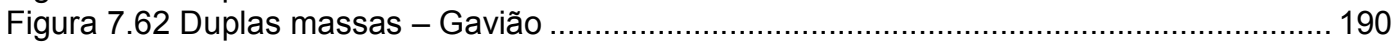

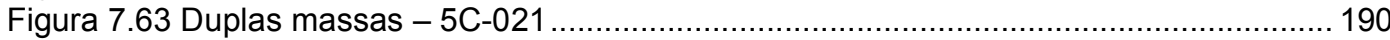

Figura 7.64 Duplas massas - bacia completa .......................................................... 190

Figura 7.65 Curva de dupla massa - localização dos períodos nas medidas de radar. .......... 192

Figura 7.66 Coeficientes de correlação das alturas médias em função da área ..................... 193

Figura 7.67 Coeficientes de correlação - alturas médias diárias - Bacia total ......................... 194

Figura 7.68 RMSE - h médio diário ....................................................................... 194

Figura 7.69 Retas de regressão - altura médias de chuva. .......................................... 195

Figura 7.70 Número médio de dias no período de estudo onde ocorre simultaneamente leitura de $\mathrm{h}$ médio na bacia inferior a $0,1 \mathrm{~mm}$.

Figura 7.71 Número médio de dias no período de estudo onde ocorre leitura de h médio na bacia inferior a $0,1 \mathrm{~mm}$ no método do IQD e superior a $1 \mathrm{~mm}$ no Radar. Radar "vê" chuva onde o pluviômetro não "vê".

Figura 7.72 Número médio de dias onde ocorre leitura de h médio na bacia inferior a $0,1 \mathrm{~mm}$ no Radar e superior a $1 \mathrm{~mm}$ no método do IQD. Pluviômetro "vê" chuva onde o Radar não "vê".

Figura 7.73 Diferença entre os valores de h médio diário do radar e de pluviômetro em função das alturas médias obtidas pelo Método do Inverso do Quadrado da Distância. .............. 199

Figura 7.74 Valor médio de h médio diário para a maior bacia por faixa de umidade ............. 200

Figura 7.75 Distribuição percentual da quantidade de dias por faixa de umidade de todo o

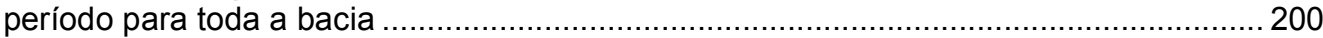

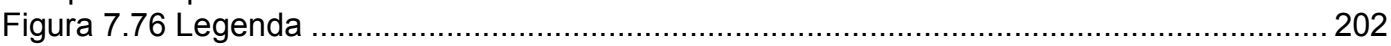

Figura 7.77 \% Diferenças Anuais - Perdizes............................................................ 202

Figura 7.78 \% Diferenças Anuais - Geraldo ............................................................ 202

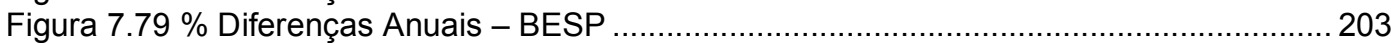

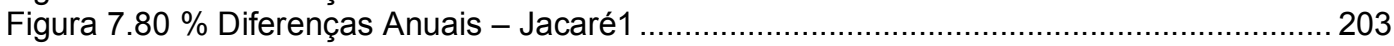

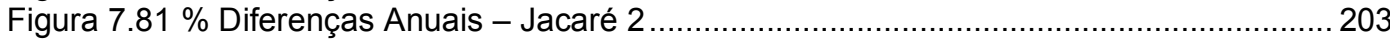




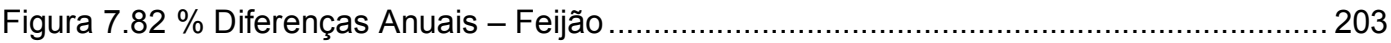

Figura 7.83 \% Diferenças Anuais - S.José................................................................. 203

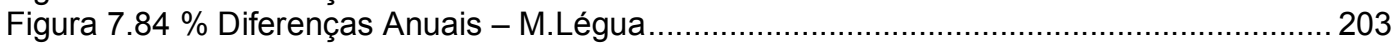

Figura 7.85 \% Diferenças Anuais - Sit.. Esp. ............................................................. 203

Figura 7.86 \% Diferenças Anuais - Inácio ..................................................................... 203

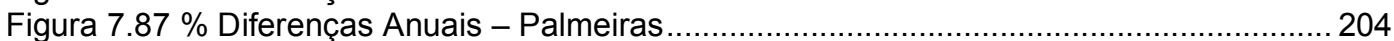

Figura 7.88 \% Diferenças Anuais - Porto ............................................................... 204

Figura 7.89 \% Diferenças Anuais - Gavião ............................................................ 204

Figura 7.90 \% Diferenças Anuais - 5C-021 ........................................................... 204

Figura 7.91 \% Diferenças Anuais - Bacia Total...................................................... 205

Figura 7.92 Altura média de chuva acumulada por ano para a bacia total.......................... 206

Figura 7.93 Altura média de chuva acumulada por ano para a bacia Sítio Esperança........... 207

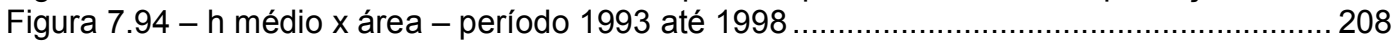

Figura 7.95 - Totais anuais médios versus área - Método Costa e Radar ............................ 209

Figura 7.96 Distribuição dos eventos diários por faixas de umidade e por anos - Bacia total. P _ pluviômetro-IQD e $\mathrm{R}-$ radar. ...................................................................... 210

Figura 7.97 Distribuição da percentagem do número de dias por faixa de umidade para todo o período por sub-bacia - IQD ........................................................................... 211

Figura 7.98 Distribuição da percentagem do número de dias por faixa de umidade para todo o

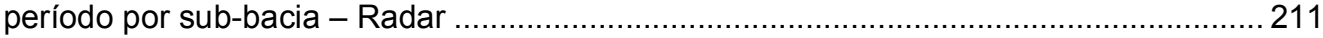

Figura 7.99 Legenda para campos anuais de precipitação .......................................... 212

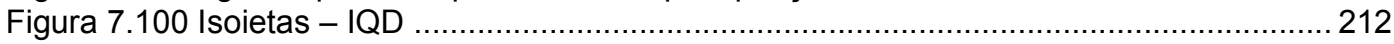

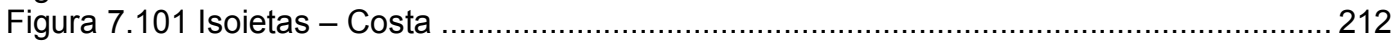

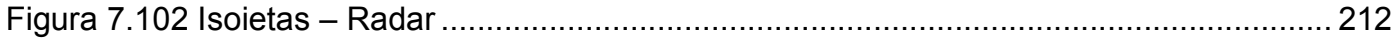

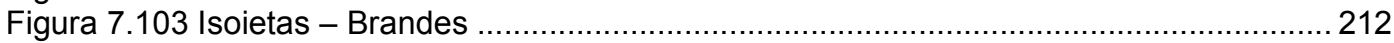

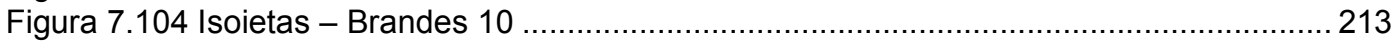

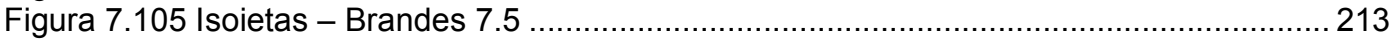

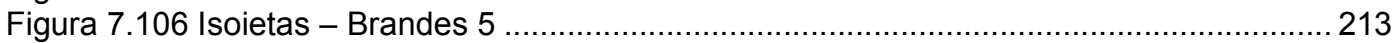

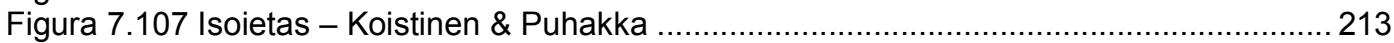

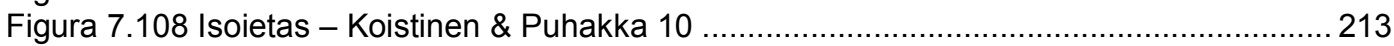

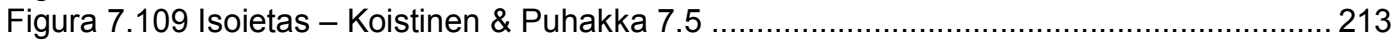

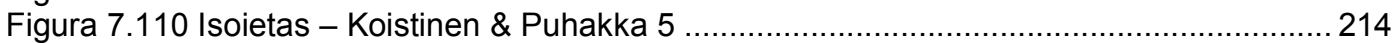

Figura 8.1 Parâmetro de armazenamento de água em função do uso do solo....................... 222

Figura 8.2 - Índices de desempenho das funções objetivo do conjunto de soluções Pareto em

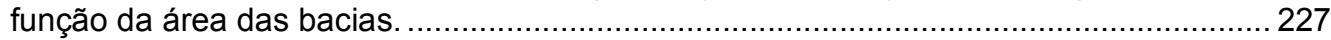

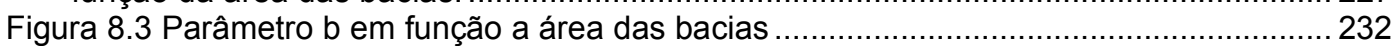

Figura 8.4 Parâmetro Kint em função a área das bacias ............................................... 232

Figura 8.5 Parâmetro Kbas em função a área das bacias .............................................. 234

Figura 8.6 Parâmetro CS em função a área das bacias ............................................... 235

Figura 8.7 Parâmetro $\mathrm{Cl}$ em função a área das bacias .................................................. 235

Figura 8.8 Parâmetro CB em função a área das bacias ................................................ 236

Figura 8.9 Parâmetro WC em função a área das bacias ............................................... 237

Figura 8.10 - Nash - Período de Calibração ............................................................. 241

Figura 8.11 Nash - Período de Validação ................................................................ 242

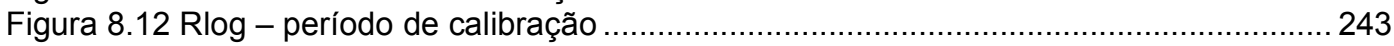

Figura 8.13 Rlog - período de validação ................................................................... 243

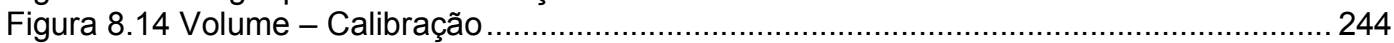

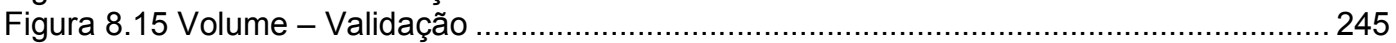

Figura 8.16 Trecho do hidrograma de calibração - bacia São José . ................................. 247

Figura 8.17 Trecho do hidrograma de validação - bacia São José ................................... 247

Figura 8.18 Variações \% de chuva e vazão por área . ................................................ 249

Figura A.1 Posição relativa das estações ................................................................... 273

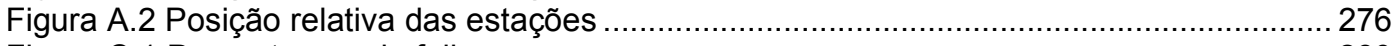

Figura C.1 Porcentagem de falhas..................................................................... 280

Figura C.2 Duplas Massas - conjunto das estações .................................................. 282

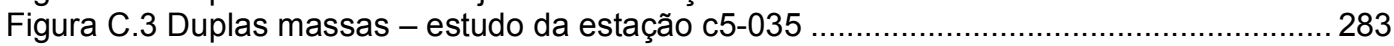

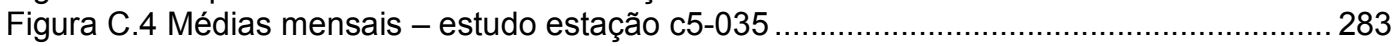

Figura C.5 Conjunto final das curvas de duplas massas. .......................................... 284

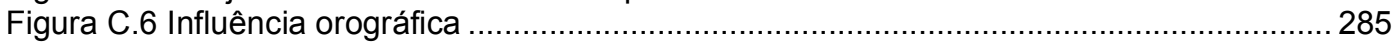

Figura C.7 Fluviograma de todas as estações - no período de 93 a 98 ............................. 286 


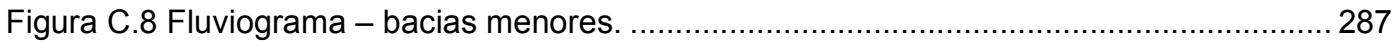

Figura C.9 Fluviograma - bacias maiores............................................................. 288

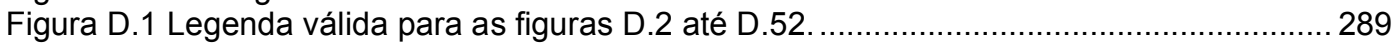

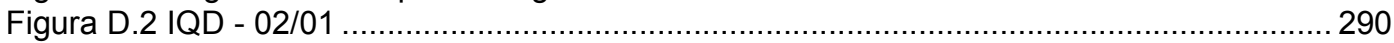

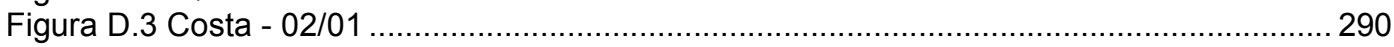

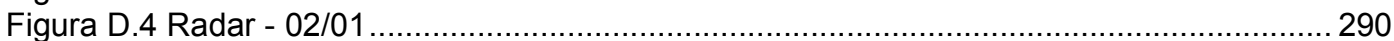

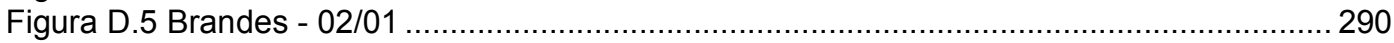

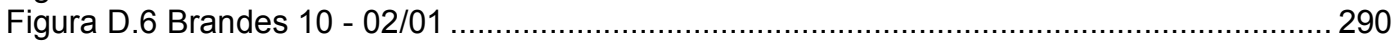

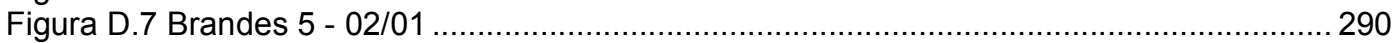

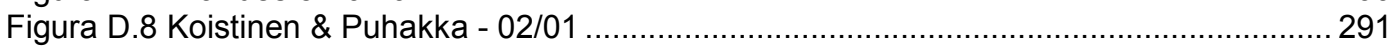

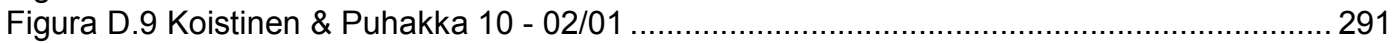

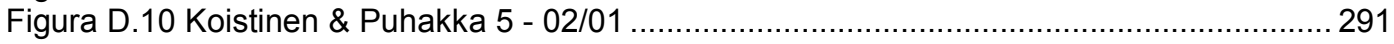

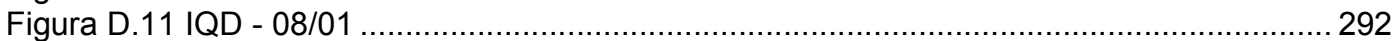

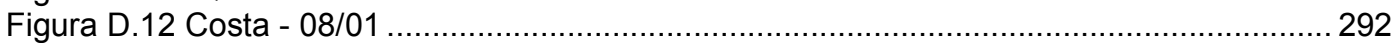

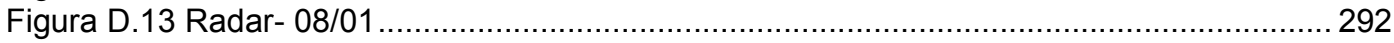

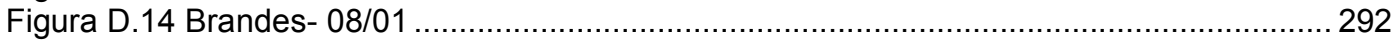

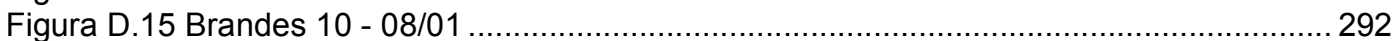

Figura D.16 Brandes 5 - 08/01 .......................................................................... 292

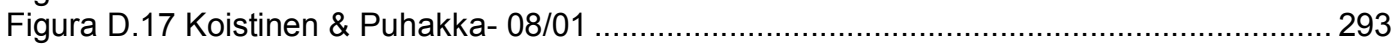

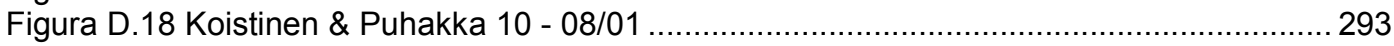

Figura D.19 Koistinen \& Puhakka 5 - 08/01 ........................................................... 293

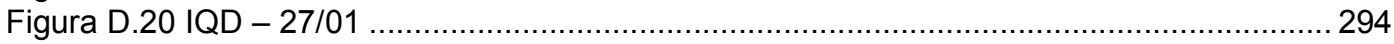

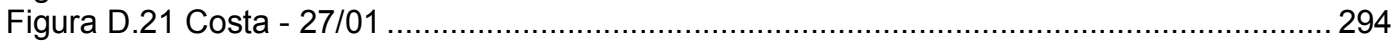

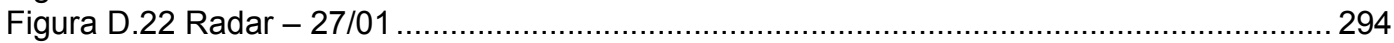

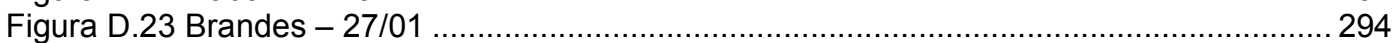

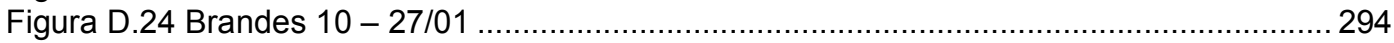

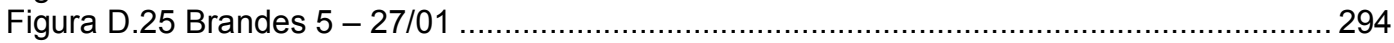

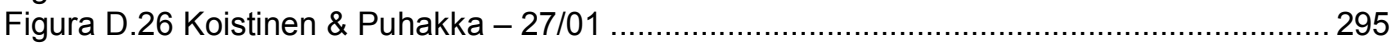

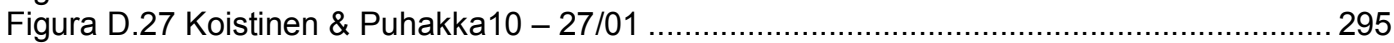

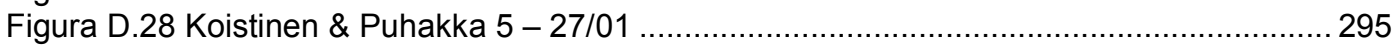

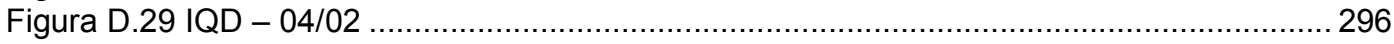

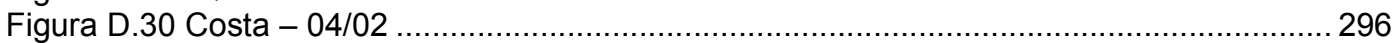

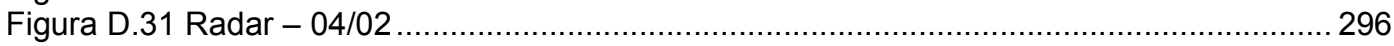

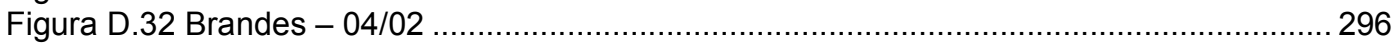

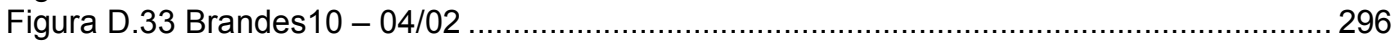

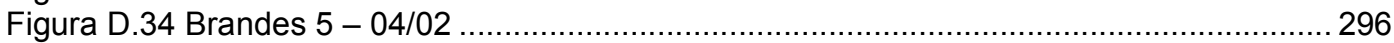

Figura D.35 Koistinen \& Puhakka $-04 / 02$............................................................ 297

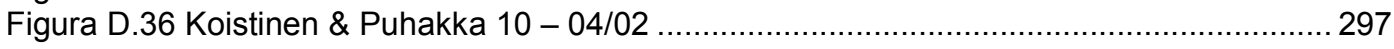

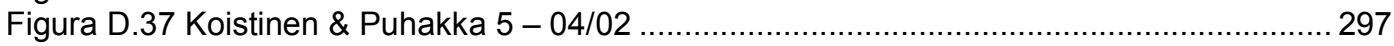

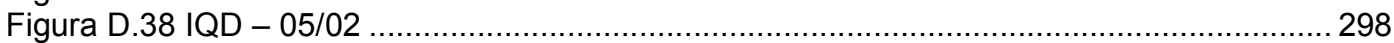

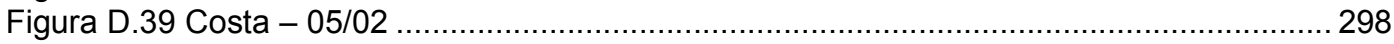

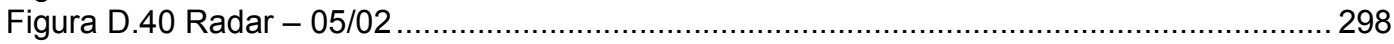

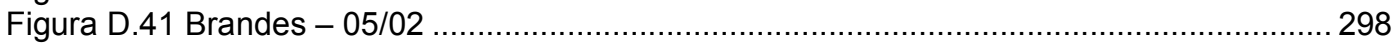

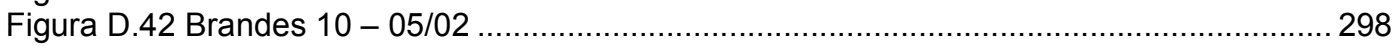

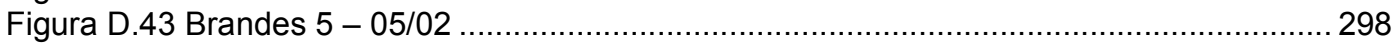

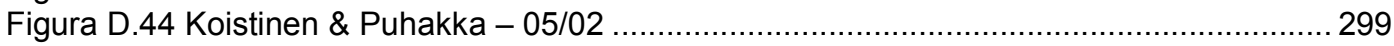

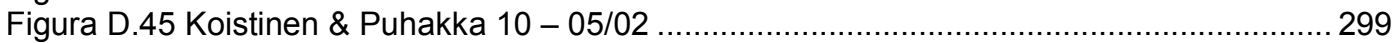

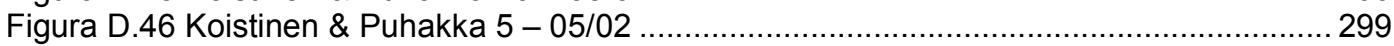

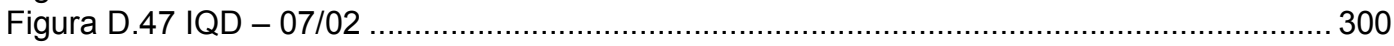

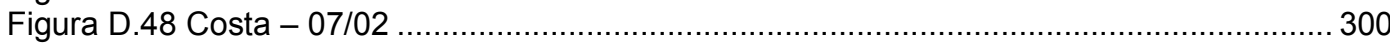

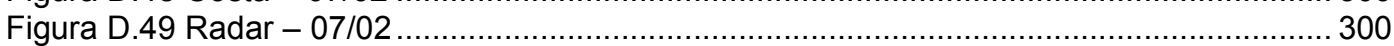

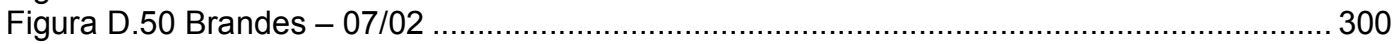

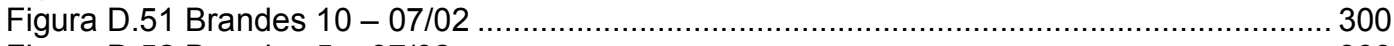

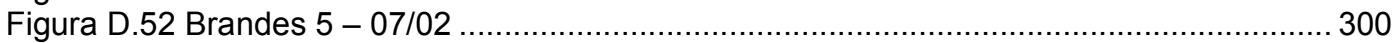

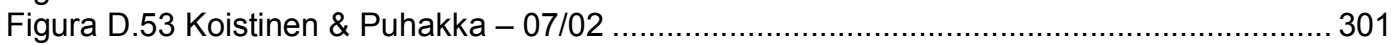

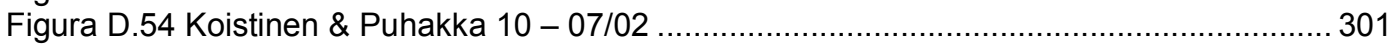

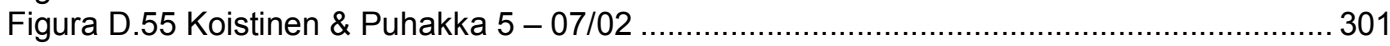

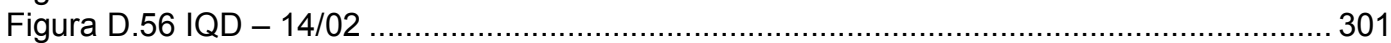

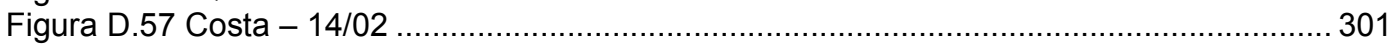

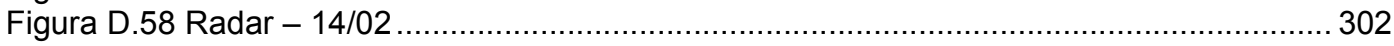




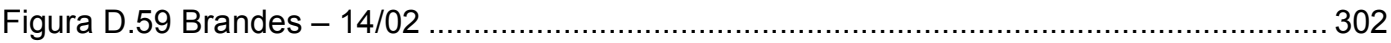

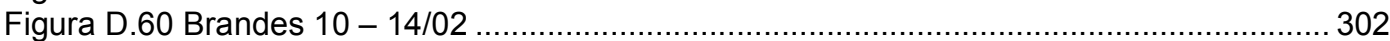

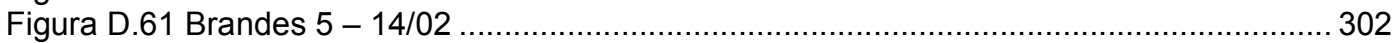

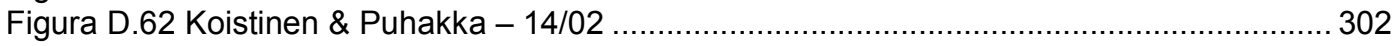

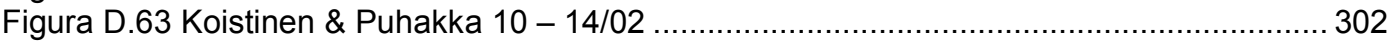

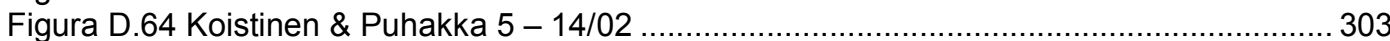

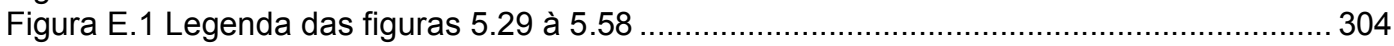

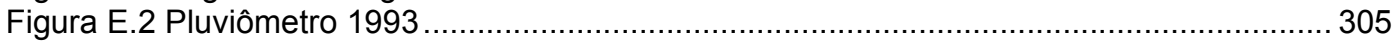

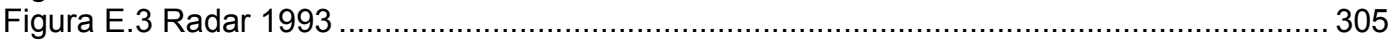

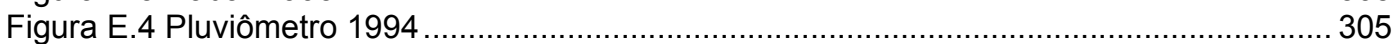

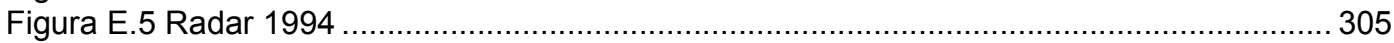

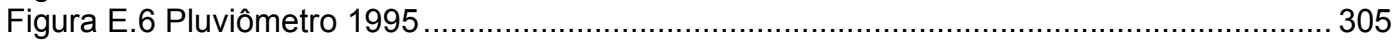

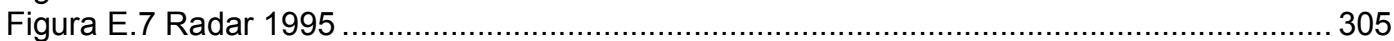

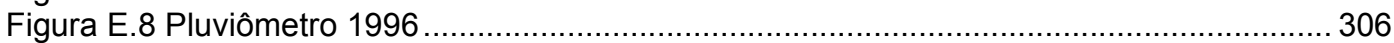

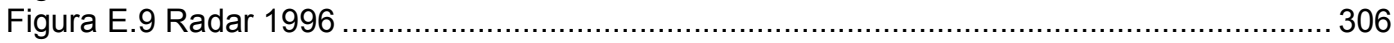

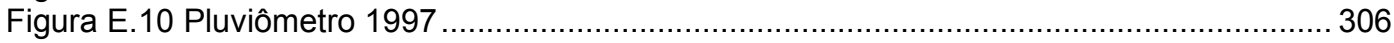

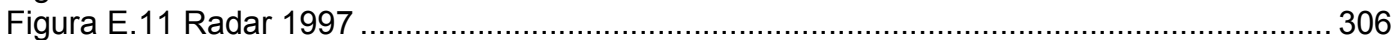

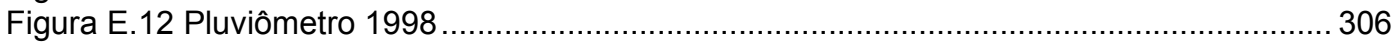

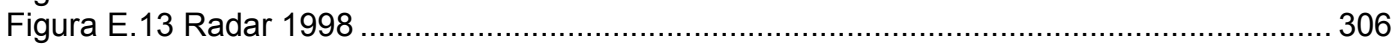

Figura E.14 Distribuição de \% de eventos - bacia Perdizes - pluviômetro ………................... 307

Figura E.15 Distribuição de \% de eventos - bacia Perdizes - radar ....................................... 307

Figura E.16 Distribuição de \% de eventos - bacia Geraldo - pluviômetro................................. 307

Figura E.17 Distribuição de \% de eventos - bacia Geraldo - radar ........................................ 307

Figura E.18 Distribuição de \% de eventos - bacia BESP - pluviômetro ………....................... 307

Figura E.19 Distribuição de \% de eventos - bacia BESP radar ................................................ 307

Figura E.20 Distribuição de \% de eventos - bacia Jacaré 1 pluviômetro .................................. 308

Figura E.21 Distribuição de \% de eventos - bacia Jacaré 1 radar .............................................308

Figura E.22 Distribuição de \% de eventos - bacia Jacaré 2 pluviômetro ..................................308

Figura E.23 Distribuição de \% de eventos - bacia Jacaré 2 - pluviômetro............................... 308

Figura E.24 Distribuição de \% de eventos - bacia Feijão - pluviômetro....................................... 308

Figura E.25 Distribuição de \% de eventos - bacia Feijão - radar ............................................ 308

Figura E.26 Distribuição de \% de eventos - bacia São José - pluviômetro ................................309

Figura E.27 Distribuição de \% de eventos - bacia São José - radar....................................... 309

Figura E.28 Distribuição de \% de eventos - bacia Meia Légua - pluviômetro........................... 309

Figura E.29 Distribuição de \% de eventos - bacia Meia Légua - radar. ................................. 309

Figura E.30 Distribuição de \% de eventos - bacia Sítio Esperança - pluviômetro .................... 309

Figura E.31 Distribuição de \% de eventos - bacia Sítio Esperança radar .............................. 309

Figura E.32 Distribuição de \% de eventos - bacia Sto.Inácio - pluviômetro ............................. 310

Figura E.33 Distribuição de \% de eventos - bacia Sto. Inácio - radar......................................310

Figura E.34 Distribuição de \% de eventos - bacia Palmeiras - pluviômetro ..............................310

Figura E.35 Distribuição de \% de eventos - bacia Palmeiras - radar ..................................... 310

Figura E.36 Distribuição de \% de eventos - bacia Porto - pluviômetro .................................... 310

Figura E.37 Distribuição de \% de eventos - bacia Porto - radar ............................................ 310

Figura E.38 Distribuição de \% de eventos - bacia Gavião - pluviômetro .................................. 311

Figura E.39 Distribuição de \% de eventos - bacia Gavião - radar .......................................... 311

Figura E.40 Distribuição de \% de eventos - bacia 5C-021 - pluviômetro................................. 311

Figura E.41 Distribuição de \% de eventos - bacia 5C-021 radar ........................................... 311

Figura E.42 Distribuição de \% de eventos - bacia total - pluviômetro..................................... 311

Figura E.43 Distribuição de \% de eventos - bacia total - radar ............................................. 311

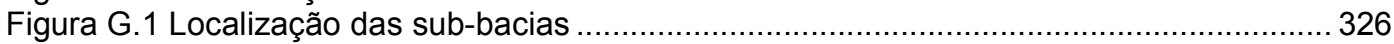

Figura G.2 Parâmetros - Solução Pareto - Bacia Perdizes ..................................................... 336

Figura G.3 Parâmetros - Solução Pareto -Bacia Feijão ……............................................. 337

Figura G.4 Parâmetros - Solução Pareto -Bacia Santo Inácio .............................................. 338

Figura G.5 Parâmetros - Solução Pareto -Bacia São José ................................................... 339

Figura G.6 Parâmetros - Solução Pareto -Bacia BESP. ..................................................... 340

Figura G.7 Parâmetros - Solução Pareto -Bacia Meia Légua ................................................ 341

Figura G.8 Parâmetros - Solução Pareto -Bacia Sítio Esperança ......................................... 342

Figura G.9 Parâmetros - Solução Pareto -Bacia Palmeiras ................................................... 343

Figura G.10 Parâmetros - Solução Pareto -Bacia Porto ……….......................................... 344

Figura G.11 Parâmetros - Solução Pareto -Bacia Gavião................................................... 345 
Figura H.1 Hidrograma - Estudo de sensibilidade - parâmetro b .................................. 346

Figura H.2 Hidrograma - Estudo de sensibilidade - parâmetro Kint.................................... 347

Figura H.3 Hidrograma - Estudo de sensibilidade - parâmetro Kbas ................................. 347

Figura H.4 Hidrograma - Estudo de sensibilidade - parâmetro Cs .................................... 348

Figura H.5 Hidrograma - Estudo de sensibilidade - parâmetro Cl ...................................... 348

Figura H.6 Hidrograma - Estudo de sensibilidade - parâmetro CB ..................................... 349

Figura H.7 Hidrograma - Estudo de sensibilidade - parâmetro WC .................................... 349

Figura I.1 Hidrograma - Perdizes - Calibração - IQD - Costa - Radar .............................. 351

Figura I.2 Hidrograma - Perdizes - Calibração - Métodos Brandes.................................. 351

Figura I.3 Hidrograma - Perdizes -Calibração - Métodos Koistinen\&Puhakka..................... 351

Figura I.4 Hidrograma - Perdizes - Validação - IQD - Costa - Radar................................ 352

Figura I.5 Hidrograma - Perdizes - Validação - Métodos Brandes ................................... 352

Figura I.6 Hidrograma - Perdizes - Validação - Métodos Koistinen\&Puhakka ...................... 352

Figura I.7 Hidrograma - BESP - Calibração - IQD - Costa - Radar ................................. 353

Figura I.8 Hidrograma - BESP - Calibração - Métodos Brandes .................................... 353

Figura I.9 Hidrograma - BESP - Calibração - Métodos Koistinen\&Puhakka ....................... 353

Figura I.10 Hidrograma - BESP - Validação - IQD - Costa - Radar .................................. 354

Figura I.11 Hidrograma - BESP - Validação - Métodos Brandes ........................................ 354

Figura I.12 Hidrograma - BESP - Validação - Métodos KP ........................................ 354

Figura I.13 Hidrograma - Feijão - Calibração - IQD - Costa - Radar ................................. 355

Figura I.14 Hidrograma - Feijão - Calibração - Métodos Brandes .................................... 355

Figura I.15 Hidrograma - Feijão - Calibração - Métodos Koisatinen\&Puhakka ..................... 355

Figura I.16 Hidrograma - Feijão - Validação - IQD - Costa - Radar ................................. 356

Figura I.17 Hidrograma - Feijão - Validação- Métodos Brandes ....................................... 356

Figura I.18 Hidrograma - Feijão - Validação - Métodos Koistinen\&Puhakka ......................... 356

Figura I.19 Hidrograma - São José - Calibração - IQD - Costa - Radar ............................. 357

Figura I.20 Hidrograma - São José - Calibração- Métodos Brandes.................................. 357

Figura I.21 Hidrograma - São José - Calibração- Métodos Koistinen\&Puhakka..................... 357

Figura I.22 Hidrograma - São José - Validação- IQD - Costa - Radar............................ 358

Figura I.23 Hidrograma - São José - Validação- Métodos Brandes ..................................... 358

Figura I.24 Hidrograma - São José - Validação- Métodos Koistinen-Puhakka. ..................... 358

Figura I.25 .Hidrograma - Meia Légua - Calibração - IQD - Costa - Radar ........................ 359

Figura I.26 Hidrograma - Meia Légua - Calibração - Métodos Brandes ............................... 359

Figura I.27 Hidrograma - Meia Légua - Calibração - Métodos Koistinen-Puhakka. ............... 359

Figura I.28 Hidrogramas - Meia Légua - Validação - IQD -Costa - Radar .......................... 360

Figura I.29 Hidrogramas - Meia Légua - Validação - Métodos Brandes ............................... 360

Figura I.30 Hidrogramas - Meia Légua - Validação - Métodos Koistinen\&Puhakka ............... 360

Figura I.31 Hidrograma - Sítio Esperança - Calibração - IQD - Costa - Radar .................... 361

Figura I.32 Hidrogramas - Sítio Esperança - Calibração - Métodos Brandes ....................... 361

Figura I.33 Hidrogramas - Sítio Esperança - Calibração - Métodos Koistinen\&Puhakka ...... 361

Figura I.34 Hidrogramas - Sítio Esperança - Validação - IQD - Costa - Radar .................... 362

Figura I.35 Hidrogramas - Sítio Esperança - Validação - Métodos Brandes........................ 362

Figura I.36 Hidrogramas - Sítio Esperança - Validação - Métodos Koistinen\&Puhakka........ 362

Figura I.37 Hidrogramas - Inácio - Calibração - IQD - Costa - Radar............................... 363

Figura I.38 Hidrogramas - Inácio - Calibração - Métodos Brandes. ................................ 363

Figura I.39 Hidrogramas - Inácio - Calibração - Métodos Koistinen\&Puhakka. ..................... 363

Figura I.40 Hidrogramas - Inácio - Validação - IQD - Costa - Radar ............................... 364

Figura I.41 Hidrogramas - Inácio - Validação - Métodos Brandes.................................... 364

Figura I.42 Hidrogramas - Inácio - Validação - Métodos Koistinen\&Puhakka....................... 364

Figura I.43 Hidrogramas - Palmeiras - Calibração - IQD - Costa - Radar .......................... 365

Figura I.44 Hidrogramas - Palmeiras - Calibração - Métodos Brandes.................................. 365

Figura I.45 Hidrogramas - Palmeiras - Calibração - Métodos Koistinen-Puhakka.................. 365

Figura I.46 Hidrogramas - Palmeiras - Validação - IQD - Costa - Radar............................ 366

Figura I.47 Hidrogramas - Palmeiras - Validação - Métodos Brandes ............................... 366

Figura I.48 Hidrogramas - Palmeiras - Validação - Métodos Koistinen\&Puhakka ................. 366

Figura I.49 Hidrogramas - Porto - Calibração - IQD - Costa - Radar............................... 367

Figura I.50 Hidrogramas - Porto - Calibração - Métodos Brandes .................................... 367

Figura I.51 Hidrogramas - Porto - Calibração - Métodos Koistinen\&Puhakka ........................ 367

Figura I.52 Hidrogramas - Porto - Validação - IQD - Costa - Radar .................................. 368

Figura I.53 Hidrogramas - Porto - Validação - Métodos Brandes ................................... 368 
Figura I.54 Hidrogramas - Porto - Validação - Métodos Koistinen\&Puhakka....................... 368

Figura I.55 Hidrogramas - Gavião - Calibração - IQD - Costa - Radar ................................ 369

Figura I.56 Hidrogramas - Gavião - Calibração - Métodos Brandes ................................... 369

Figura I.57 Hidrogramas - Gavião - Calibração - Métodos Koitinen\&Puhakka ....................... 369

Figura I.58 Hidrogramas - Gavião - Validação - IQD - Costa - Radar ................................. 370

Figura I.59 Hidrogramas - Gavião - Validação - Métodos Brandes........................................ 370

Figura I.60 Hidrogramas - Gavião - Validação - Métodos Koistinen\&Puhakka..................... 370

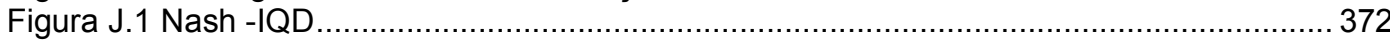

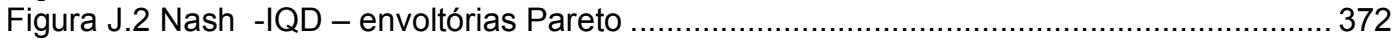

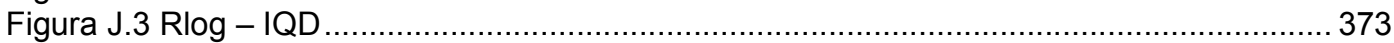

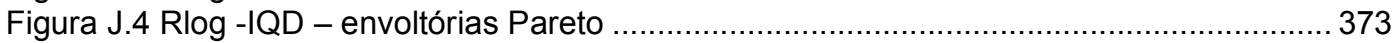

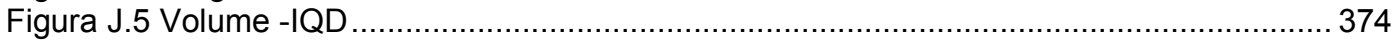

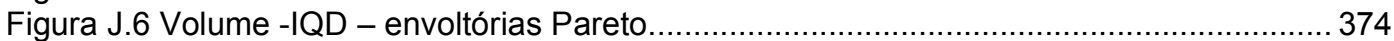

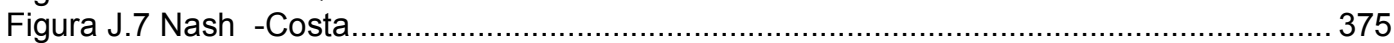

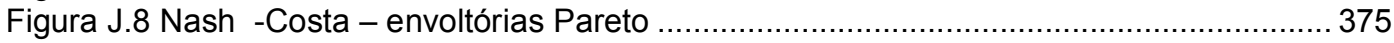

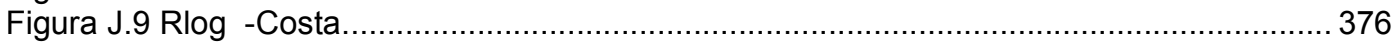

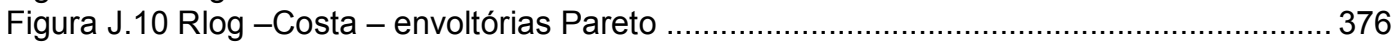

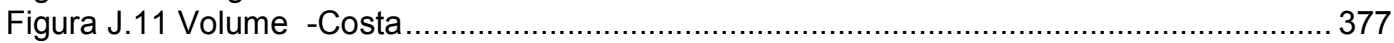

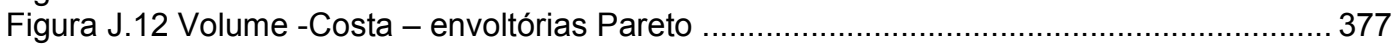

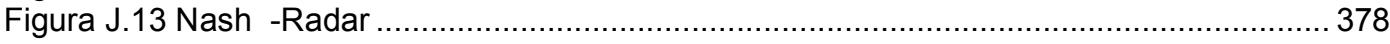

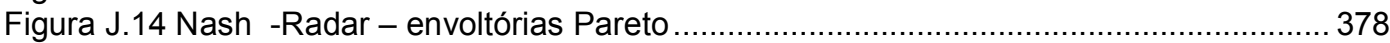

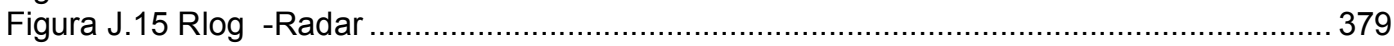

Figura J.16 Rlog -Radar - envoltórias Pareto ......................................................... 379

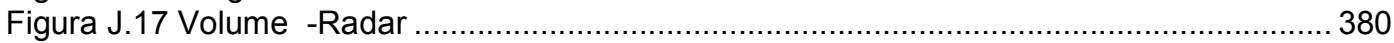

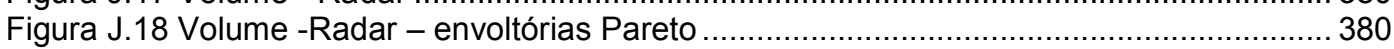

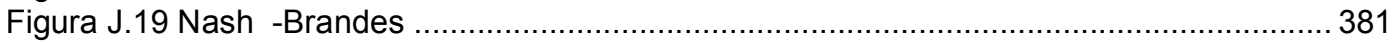

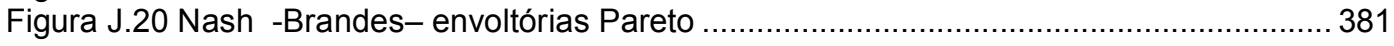

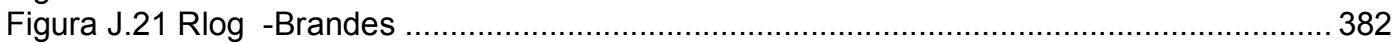

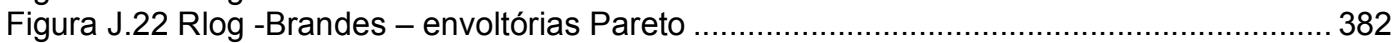

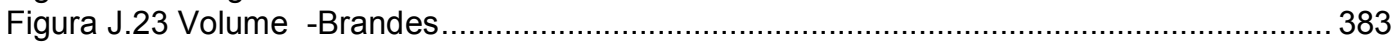

Figura J.24 Volume -Brandes - envoltórias Pareto ..................................................... 383

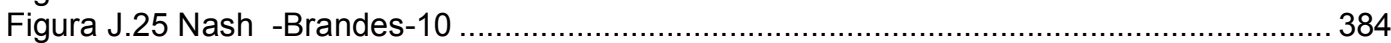

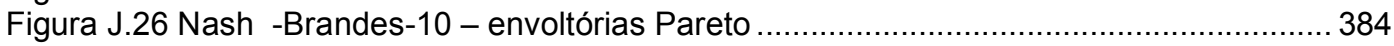

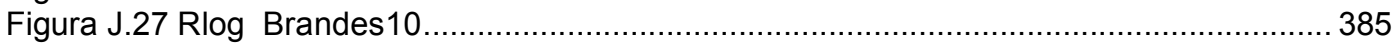

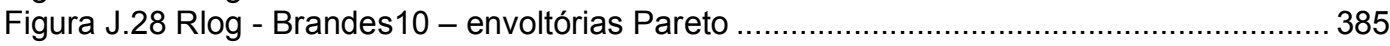

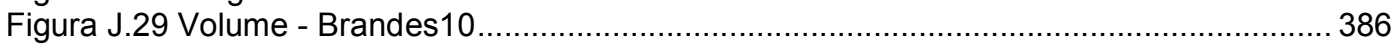

Figura J.30 Volume - Brandes 10 - envoltórias Pareto ................................................ 386

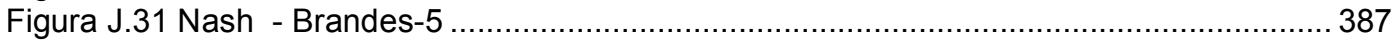

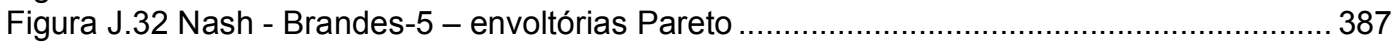

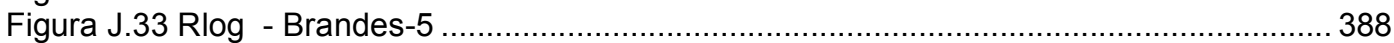

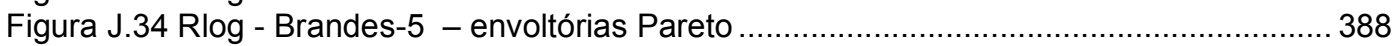

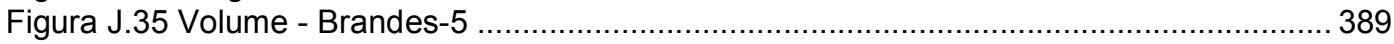

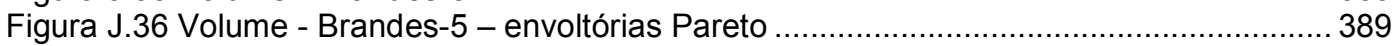

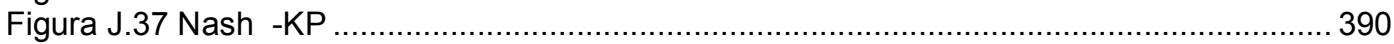

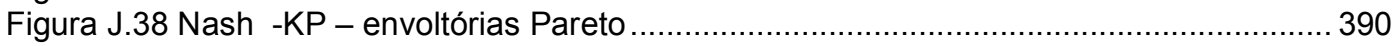

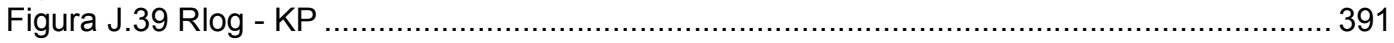

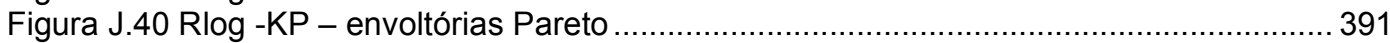

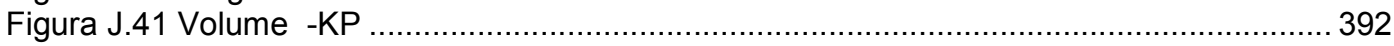

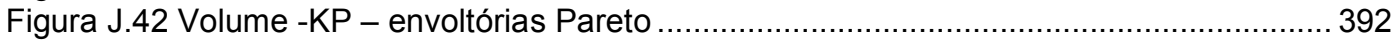

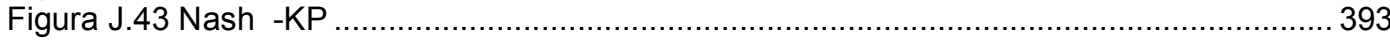

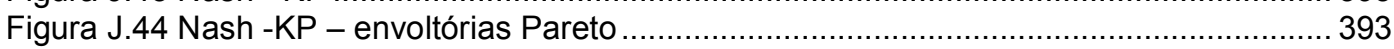

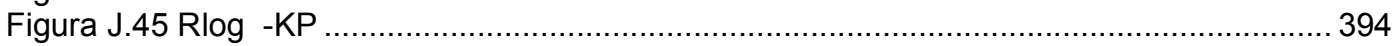

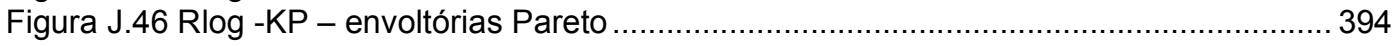

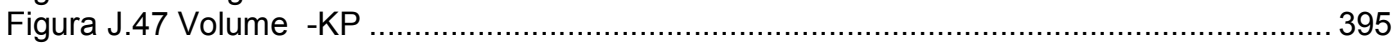

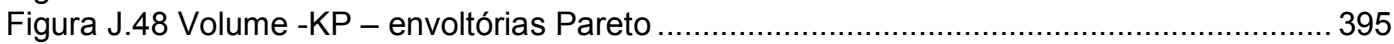

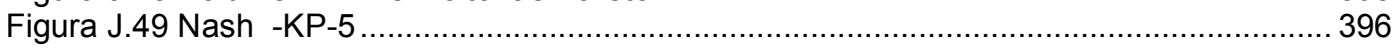

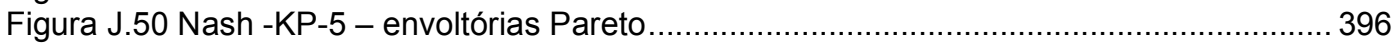

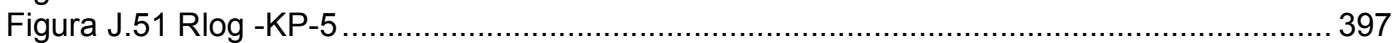

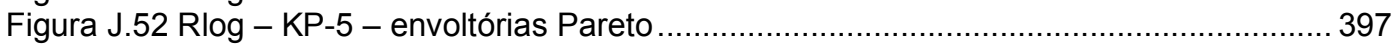

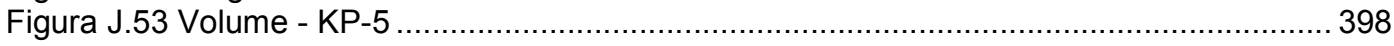




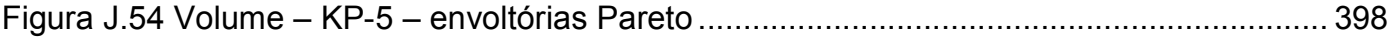

Figura K.1 Hidrograma - 5C-021 - período 1993 - 1998 .............................................. 399

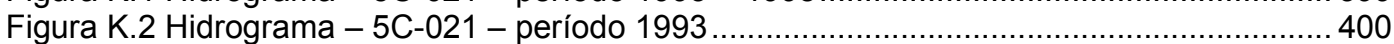

Figura K.3 Hidrograma - Bacia total - Jacaré-Guaçu - período 1993 -1998 ....................... 400 


\section{Lista de Tabelas}

Tabela 2.1 Relação entre comprimento de onda, banda e freqüência ........................................ 10

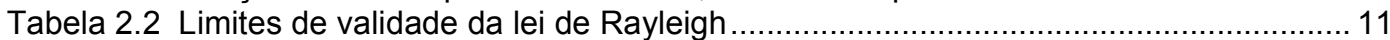

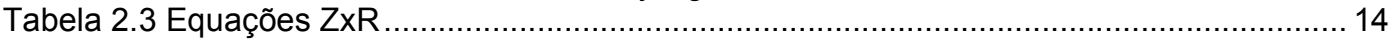

Tabela 2.4 Distâncias médias entre dois pontos tomados aleatoriamente para figuras

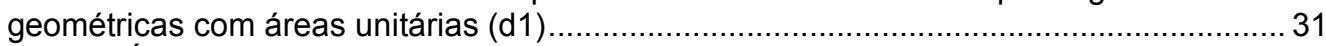

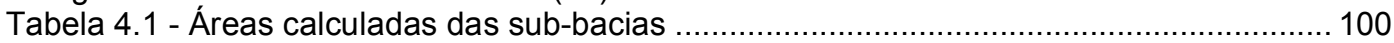

Tabela 4.2 - Quadro síntese dos métodos de composição dos campos de precipitação. ....... 102

Tabela 5.1 Características do radar banda S .................................................................. 112

Tabela 5.2 Valores dos coeficientes da equação $Z=A R^{b}$ e do coeficiente de correlação c... 114

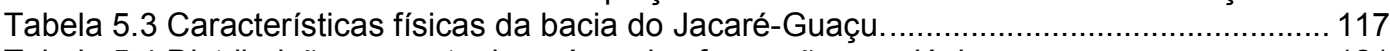

Tabela 5.4 Distribuição percentual em área das formações geológicas .................................. 121

Tabela 5.5 Distribuição percentual em área dos sistemas de relevo por sub-bacia ................ 123

Tabela 5.6- Distribuição percentual em área das classes de declividade .................................. 126

Tabela 5.7 Distribuição percentual em área dos tipos de solo ............................................ 126

Tabela 5.8 Distribuição percentual em área por sub-bacia das classes de uso ........................ 129

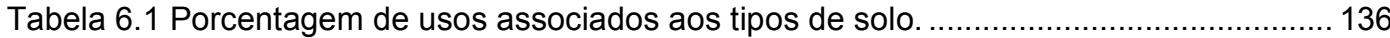

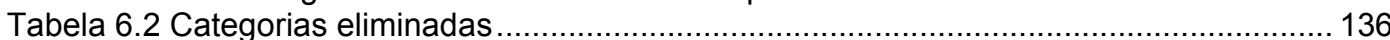

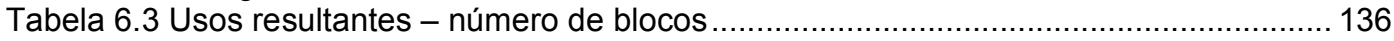

Tabela 6.4 Valores de IAF encontrados na literatura......................................................... 140

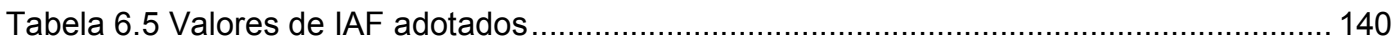

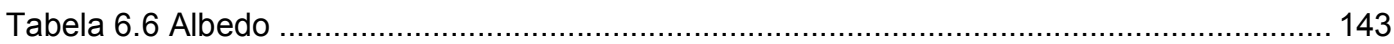

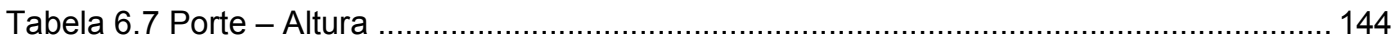

Tabela 6.8 Resistência superficial RS - em boas condições de umidade ……….................. 144

Tabela 6.9 Capacidade de armazenamento do solo ........................................................ 151

Tabela 6.10 Valores percentuais médios e desvios-padrão da umidade medidos .................. 152

Tabela 6.11 Valores médios e desvios padrão dos reservatórios do modelo .......................... 152

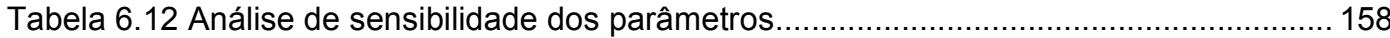

Tabela 6.13 Faixa de variação dos parâmetros.................................................................... 158

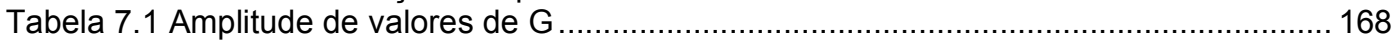

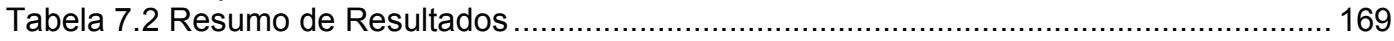

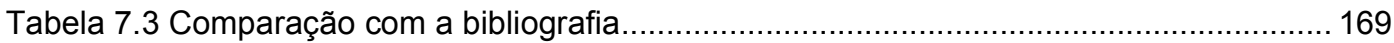

Tabela 7.4 Exemplo de análise espacial - dia 01/01/95 _..................................................... 174

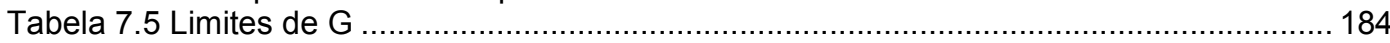

Tabela 7.6 Retas de ajuste de $\bar{h}$ diário calculado pelos diversos métodos versus $\bar{h}$ do Método

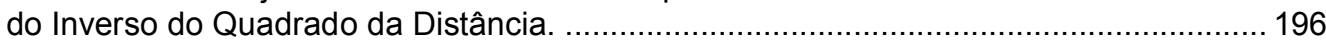

Tabela 7.7 \% Distribuição de h médio próximos a zero........................................................ 196

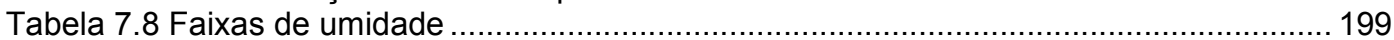

Tabela 7.9 Diferenças percentuais entre a média dos hmédios diários do radar e métodos compostos relativos aos métodos baseados somente em pluviômetros. ..........................201

Tabela 8-1 Limites dos 19 parâmetros - primeira fase de calibração .................................... 220

Tabela 8-2 Limites dos 7 parâmetros - Segunda fase de calibração ...................................... 221

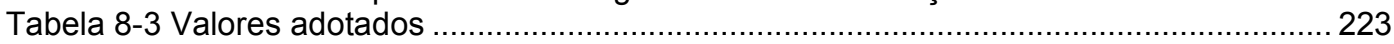

Tabela 8-4 Quadro resumo da qualidade de ajuste - Primeira fase de calibração ................... 224

Tabela 8-5 Quadro resumo da qualidade de ajuste - Segunda fase de calibração ................... 227

Tabela 8-6 Análise comparativa de desempenho entre as duas etapas de calibração ............ 229

Tabela 8-7 Funções Objetivo - Análise de Consistência..................................................... 231

Tabela 8-8 Relação entre variação de chuva e vazão - resultados da bibliografia ................... 248

Tabela 8-9 Relação entre variação de chuva e vazão - resultados por bacias …...................... 248

Tabela 8-10 Tabela comparativa - série sintética e série histórica. .......................................20

Tabela B.1 Postos fluviométricos na Bacia do rio Jacaré-Guaçu com dados após 1993 ........ 277

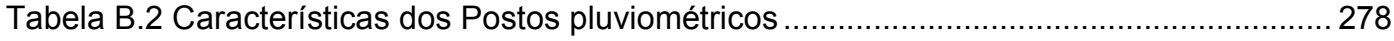

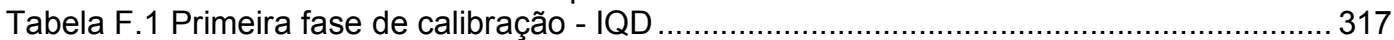

Tabela F.2 Primeira fase de calibração - Costa ................................................................... 318

Tabela F.3 Primeira fase de calibração - Radar ……........................................................ 319

Tabela F.4 Primeira fase de calibração - Brandes sem limitação ............................................ 320

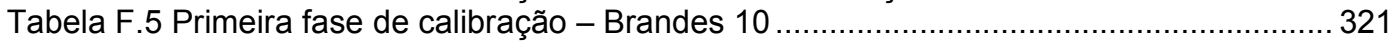


Tabela F.6 Primeira fase de calibração - Brandes 5 ................................................ 322

Tabela F.7 Primeira fase de calibração - Koistinen \& Puhakka -KP ................................... 323

Tabela F.8 Primeira fase de calibração - Koistinen \& Puhakka 10 -KP10 ........................... 324

Tabela F.9 Primeira fase de calibração - Koistinen \& Puhakka 5 -KP5 ............................... 325

Tabela G.1 Segunda fase de calibração - IQD .............................................................. 327

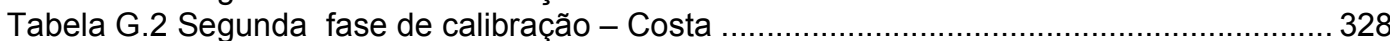

Tabela G.3 Segunda fase de calibração - Radar ..................................................... 329

Tabela G.4 Segunda fase de calibração - Brandes - sem limitação ................................. 330

Tabela G.5 Segunda fase de calibração - Brandes - Modificado G-10 ............................. 331

Tabela G.6 Segunda fase de calibração - Brandes - Modificado G-5............................ 332

Tabela G.7 Segunda fase de calibração - Koistinen-Puhakka - sem modificação ................ 333

Tabela G.8 Segunda fase de calibração - Koistinen-Puhakka - modificado - G-10 ............ 334

Tabela G.9 Segunda fase de calibração - - Koistinen-Puhakka - modificado - G-5 ............ 335

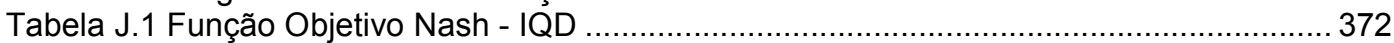

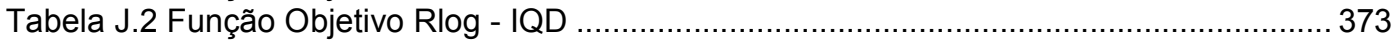

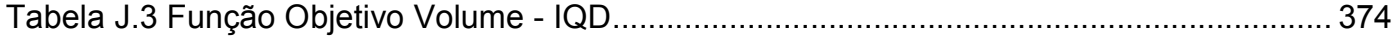

Tabela J.4 Função Objetivo Nash - Costa ........................................................................ 375

Tabela J.5 Função Objetivo Rlog - Costa ................................................................. 376

Tabela J.6 Função Objetivo Volume - Costa............................................................. 377

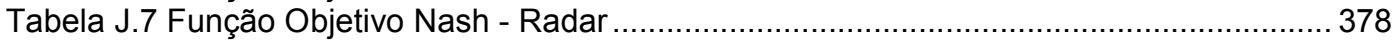

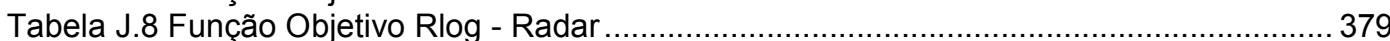

Tabela J.9 Função Objetivo Volume - Radar ......................................................... 380

Tabela J.10 Função Objetivo Nash - Brandes ........................................................... 381

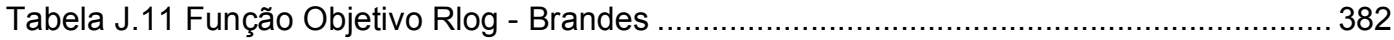

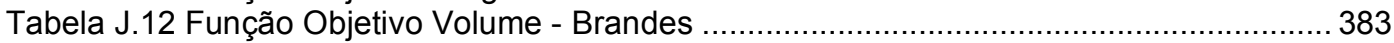

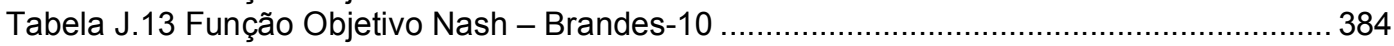

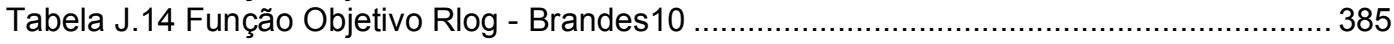

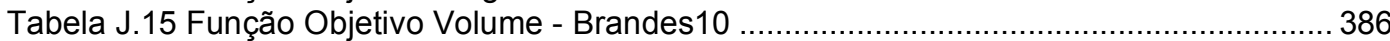

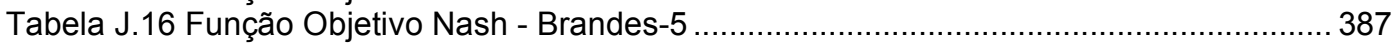

Tabela J.17 Função Objetivo Rlog - Brandes-5 ......................................................... 388

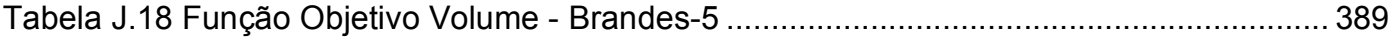

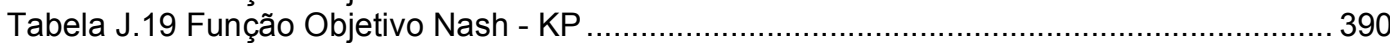

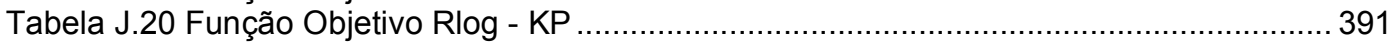

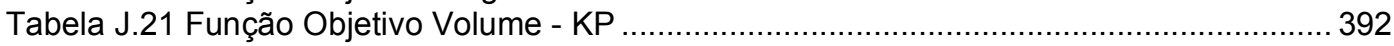

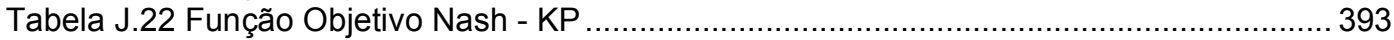

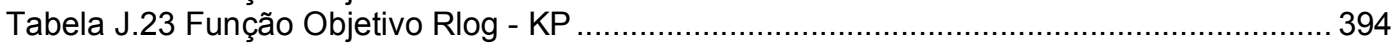

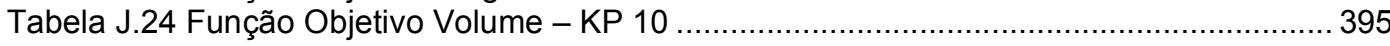

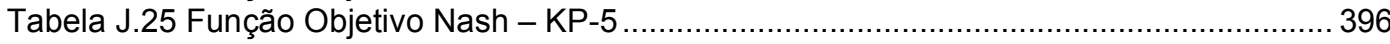

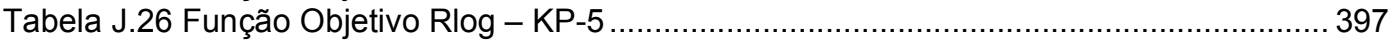

Tabela J.27 Função Objetivo Volume - KP-5 ........................................................... 398 


\section{Lista de Abreviaturas e Símbolos}
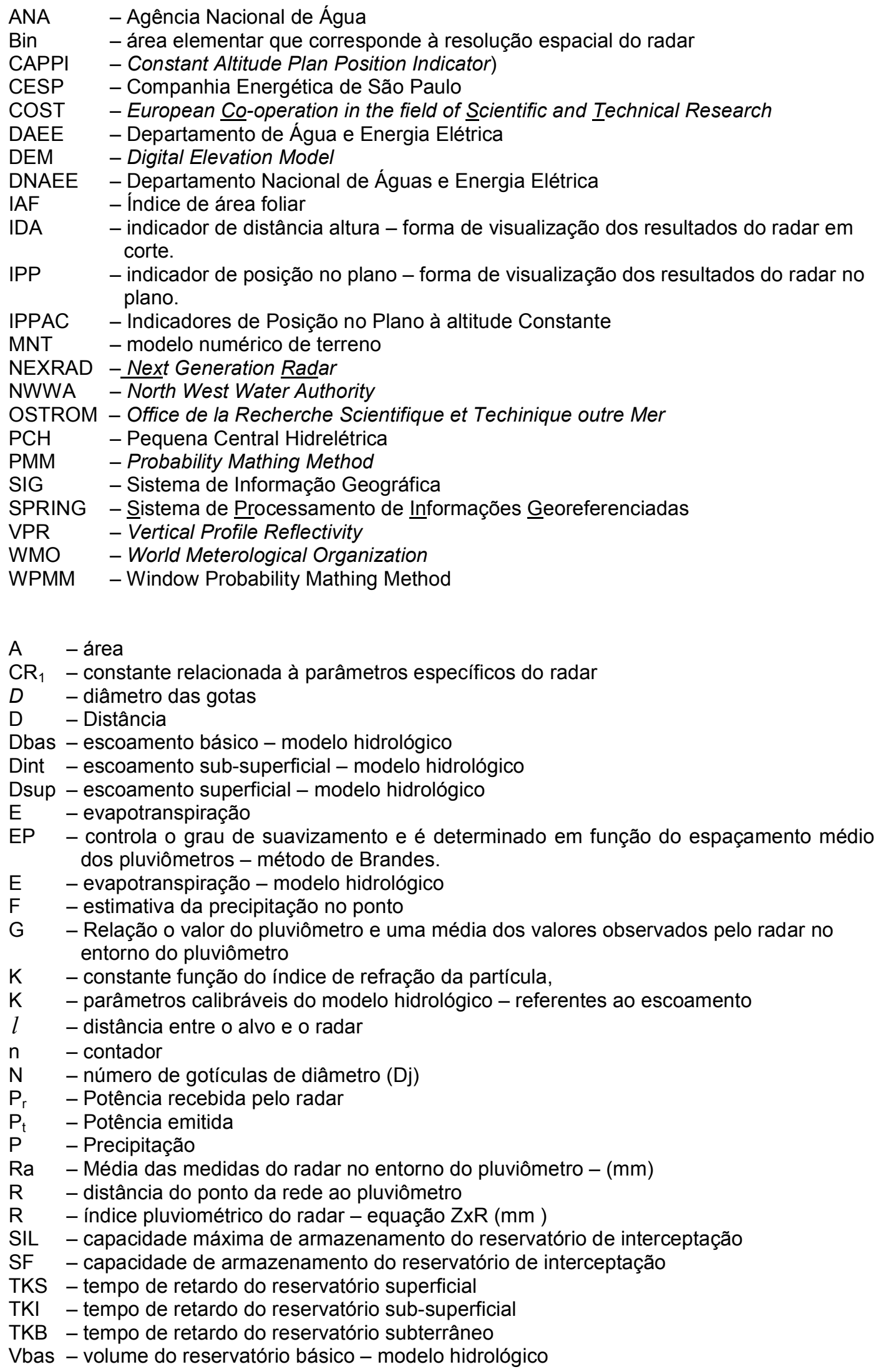


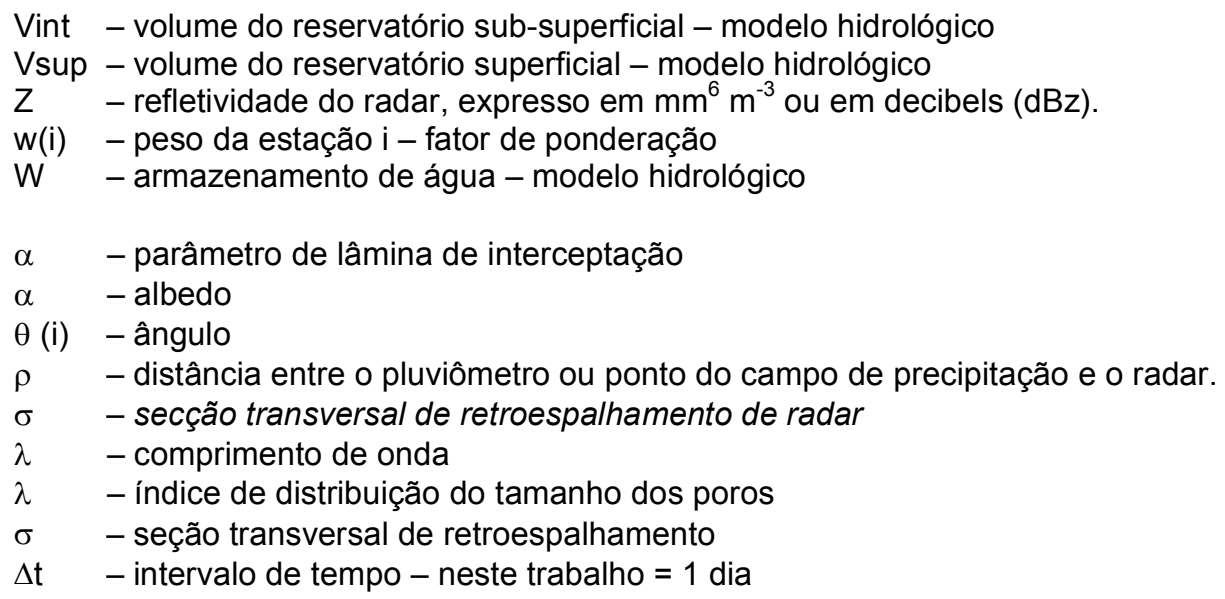




\section{Sumário}

1 INTRODUÇÃO

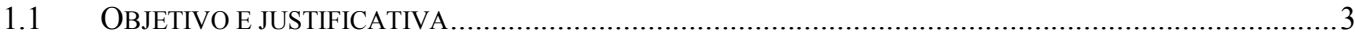

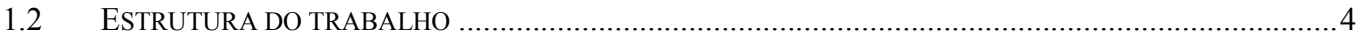

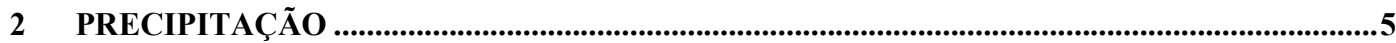

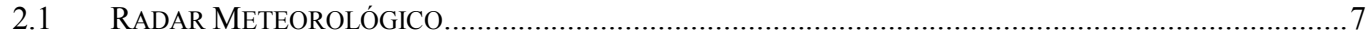

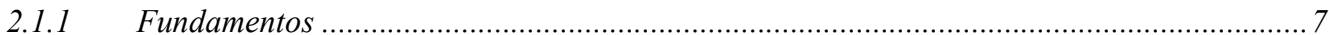

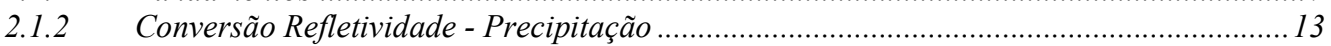

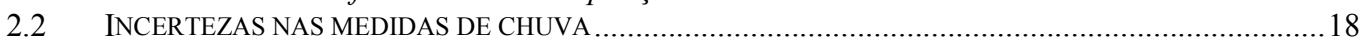

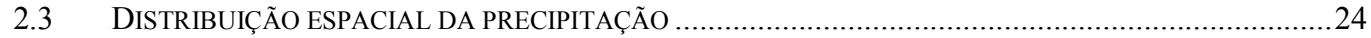

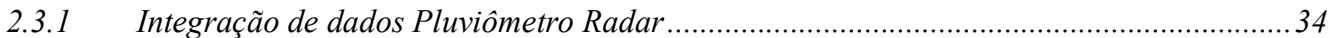

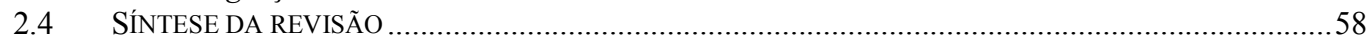

3 MODELOS CHUVA - VAZÃO .................................................................................................60

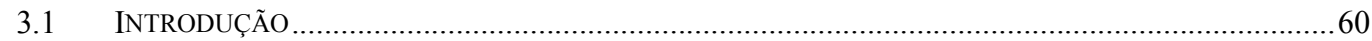

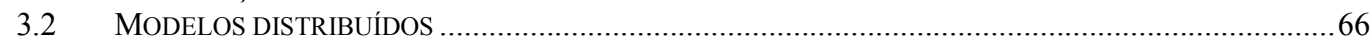

3.3 CALIBRAÇÃO DE PARÂMETROS E INCERTEZA.........................................................................74

3.4 APLICAÇÕES DE CAMPOS DE PRECIPITAÇ̃̃O EM MODELOS HIDROLÓGICOS. ...................................77

3.5 UTILIZAÇÃo DE Sistemas de INFORMAÇÕES GEOGRÁFICAS NA MODELAÇ̃̃o HIDROLÓGICA .....99

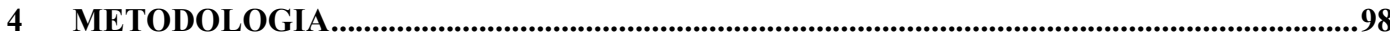

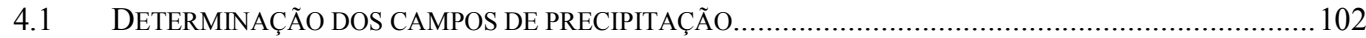

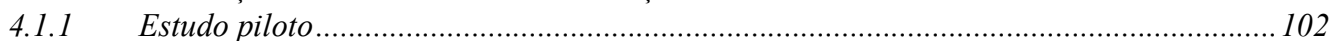

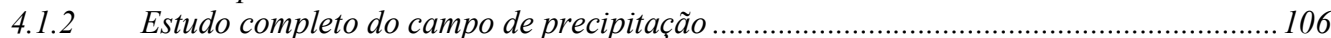

4.2 APLICAÇÃO DOS CAMPOS DE PRECIPITAÇ̃̃O AO MODELO HIDROLÓGICO …………………….......107

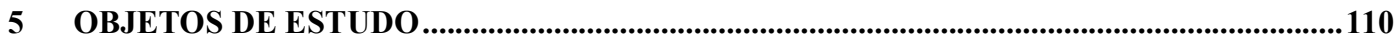

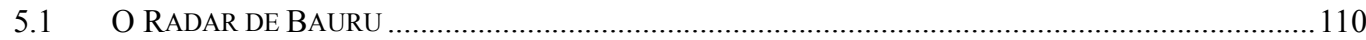

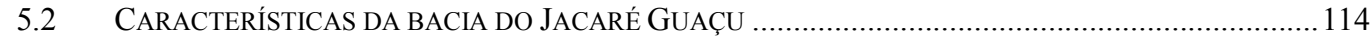

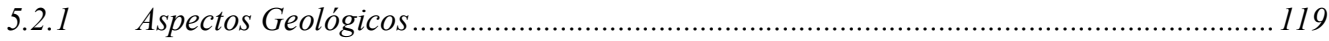

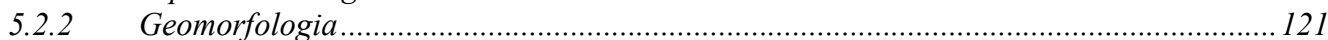

5.2.3 Carta Altimétrica e Declividade ................................................................................. 123

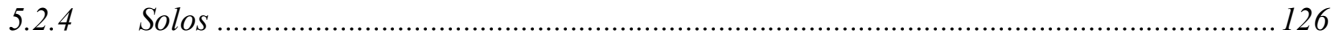

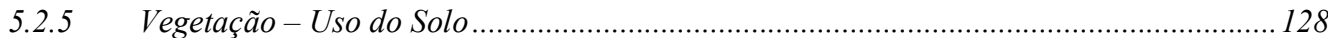

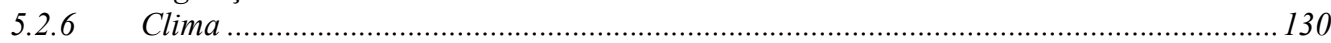

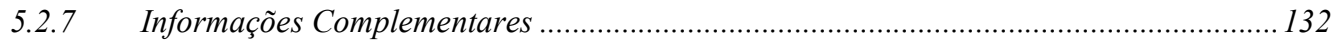

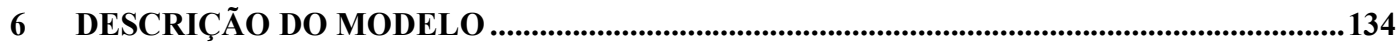

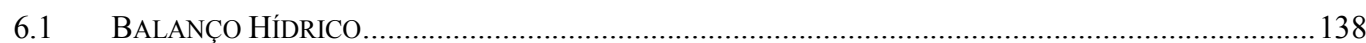

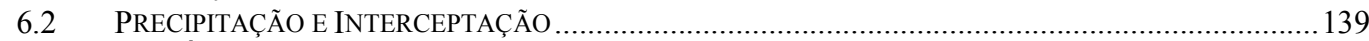

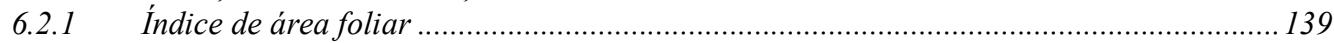

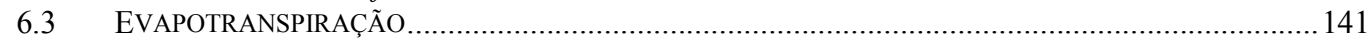

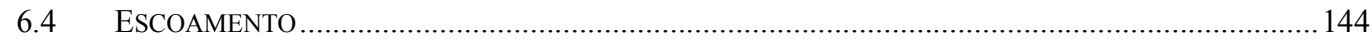

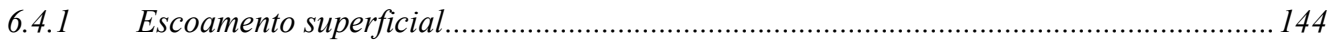

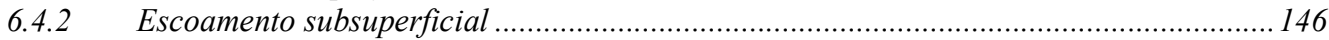

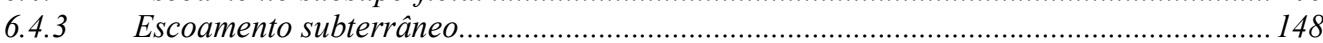

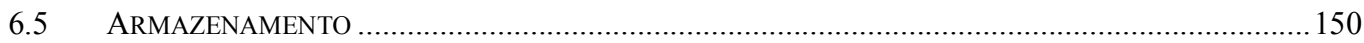

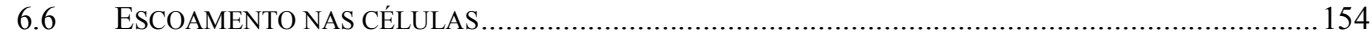

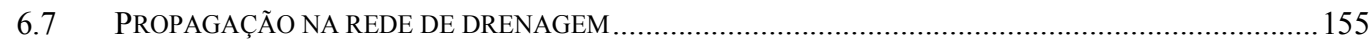

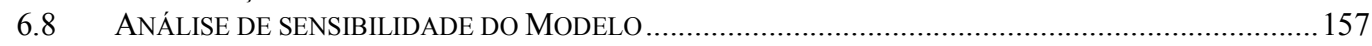

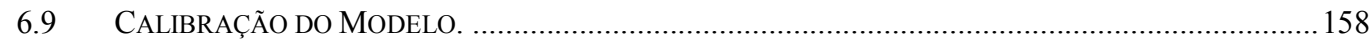

7 RESULTADOS E DISCUSSÃO: CAMPOS DE PRECIPITAÇÃO ............................................163

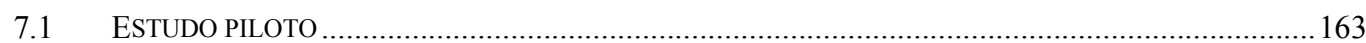

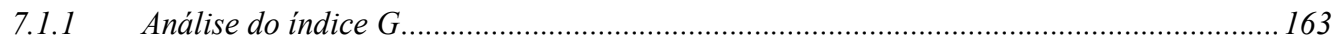

7.1.2 Comparação dos Campos de precipitação ……………............................................ 170 


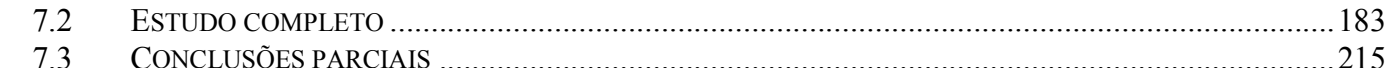

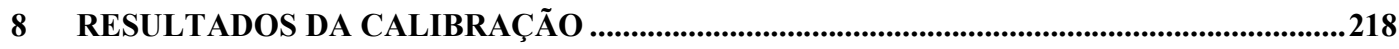

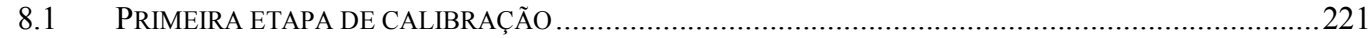

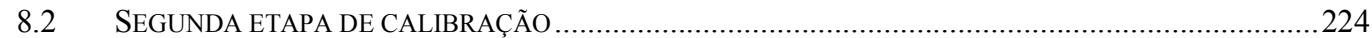

8.3 VERIFICAÇÃO DO DESEMPENHO DO MODELO NA FASE DE CALIBRAÇÃO E VALIDAÇÃO ...............238

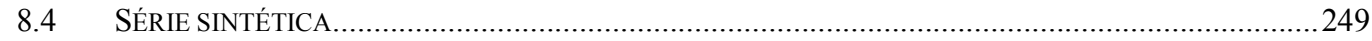

9 CONCLUSÕES, OBSERVAÇÕES E RECOMENDAÇÕES....................................................251

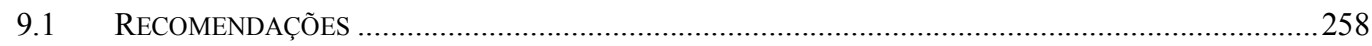

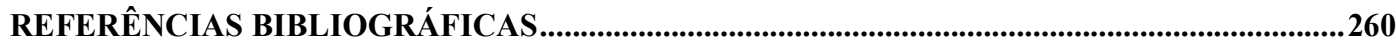

APÊNDICE A - MÉTODO COSTA \& RIGHETTO ....................................................................2273

APÊNDICE B - CARACTERÍSTICAS DOS POSTOS FLUVIOMÉTRICOS E

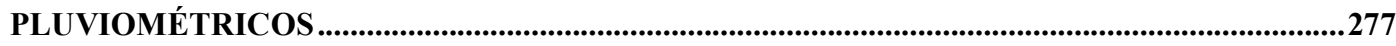

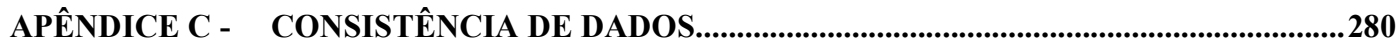

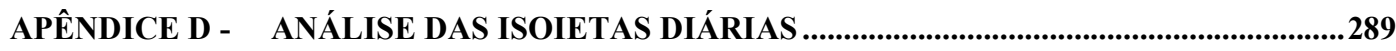

APÊNDICE E - PORCENTAGEM DE OCORRÊNCIA DE EVENTOS POR FAIXA DE

UMIDADE

APÊNDICE F - PRIMEIRA ETAPA DE CALIBRAÇÃO - FUNÇÕES OBJETIVO E FAIXAS

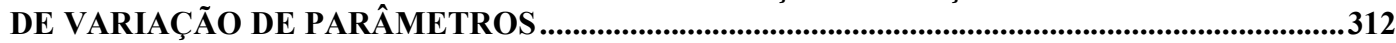

APÊNDICE G - SEGUNDA ETAPA DE CALIBRAÇÃO - FUNÇÕES OBJETIVO E FAIXAS

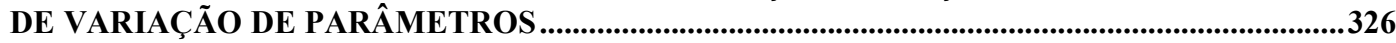

APÊNDICE H - ESTUDO DE SENSIBILIDADE - HIDROGRAMAS ........................................346

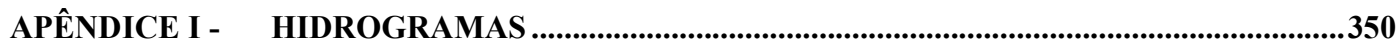

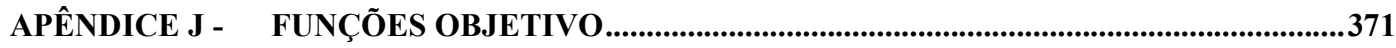

APÊNDICE K - SÉRIE SINTÉTICA ….....................................................................................399 